\title{
Granular activated carbon with grafted nanoporous polymer enhances nanoscale zero- valent iron impregnation and water contaminant removal
}

Mines, Paul D.; Uthuppu, Basil; Thirion, Damien; Jakobsen, Mogens Havsteen; Yavuz, Cafer T.; Andersen, Henrik Rasmus; Hwang, Yuhoon

\section{Published in:}

Chemical Engineering Journal

Link to article, DOI:

10.1016/j.cej.2018.01.102

Publication date:

2018

Document Version

Peer reviewed version

Link back to DTU Orbit

Citation (APA):

Mines, P. D., Uthuppu, B., Thirion, D., Jakobsen, M. H., Yavuz, C. T., Andersen, H. R., \& Hwang, Y. (2018). Granular activated carbon with grafted nanoporous polymer enhances nanoscale zero-valent iron impregnation and water contaminant removal. Chemical Engineering Journal, 339, 22-31. https://doi.org/10.1016/j.cej.2018.01.102

\section{General rights}

Copyright and moral rights for the publications made accessible in the public portal are retained by the authors and/or other copyright owners and it is a condition of accessing publications that users recognise and abide by the legal requirements associated with these rights.

- Users may download and print one copy of any publication from the public portal for the purpose of private study or research.

- You may not further distribute the material or use it for any profit-making activity or commercial gain

- You may freely distribute the URL identifying the publication in the public portal 


\section{Accepted Manuscript}

Granular activated carbon with grafted nanoporous polymer enhances nanoscale zero-valent iron impregnation and water contaminant removal

Paul D. Mines, Basil Uthuppu, Damien Thirion, Mogens H. Jakobsen, Cafer T. Yavuz, Henrik R. Andersen, Yuhoon Hwang

PII: S1385-8947(18)30118-9

DOI: https://doi.org/10.1016/j.cej.2018.01.102

Reference:

$$
\text { CEJ } 18422
$$

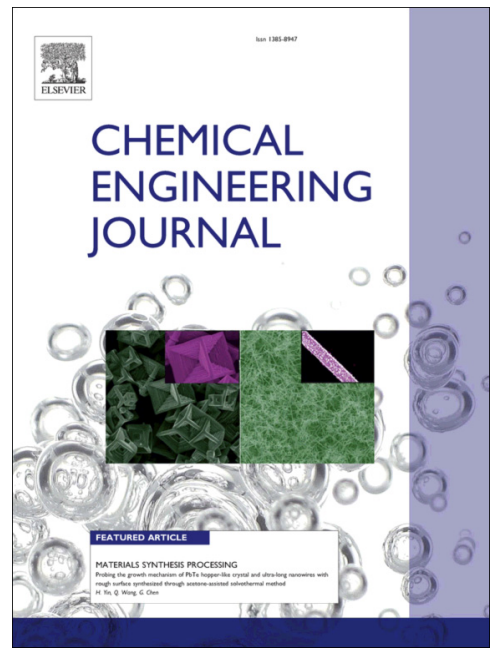

To appear in:

Chemical Engineering Journal

Received Date:

31 October 2017

Revised Date:

17 January 2018

Accepted Date:

19 January 2018

Please cite this article as: P.D. Mines, B. Uthuppu, D. Thirion, M.H. Jakobsen, C.T. Yavuz, H.R. Andersen, Y. Hwang, Granular activated carbon with grafted nanoporous polymer enhances nanoscale zero-valent iron impregnation and water contaminant removal, Chemical Engineering Journal (2018), doi: https://doi.org/10.1016/ j.cej.2018.01.102

This is a PDF file of an unedited manuscript that has been accepted for publication. As a service to our customers we are providing this early version of the manuscript. The manuscript will undergo copyediting, typesetting, and review of the resulting proof before it is published in its final form. Please note that during the production process errors may be discovered which could affect the content, and all legal disclaimers that apply to the journal pertain. 


\section{Granular activated carbon with grafted nanoporous polymer enhances nanoscale zero-valent iron impregnation and water contaminant removal}

Paul D. Mines, ${ }^{\mathrm{a}, \mathrm{b}}$ Basil Uthuppu, ${ }^{\mathrm{a}}$ Damien Thirion, ${ }^{\mathrm{c}}$ Mogens H. Jakobsen, ${ }^{\mathrm{a}}$ Cafer T. Yavuz, Henrik R. Andersen, ${ }^{\mathrm{b}}$ and Yuhoon Hwang ${ }^{\mathrm{d}, *}$

${ }^{a}$ Department of Micro- and Nanotechnology, Technical University of Denmark, Ørsteds Plads, B345c, DK-2800 Kongens Lyngby, Denmark

b Department of Environmental Engineering, Technical University of Denmark, Miljøvej. B115, DK-2800 Kongens Lyngby, Denmark

${ }^{c}$ Graduate School of EEWS, Korea Advanced Institute of Science and Technology, 291 Daehak-ro, Yuseong-gu, Daejeon 305-701, Republic of Korea

d Department of Environmental Engineering, Seoul National University of Science and Technology, 232 Gongneung-ro, Nowon-gu, Seoul 01811, Republic of Korea

*Corresponding author

Dr. Yuhoon Hwang

E-mail: yhhwang@ seoultech.ac.kr, Tel: +82-2-970-6626, Fax: +82-2-971-5776 


\begin{abstract}
Granular activated carbon was customized with a chemical grafting procedure of a nanoporous polymeric network for the purpose of nanoscale zero-valent iron impregnation and subsequent water contaminant remediation. Characterization of the prepared composite material revealed that not only was the polymer attachment and iron impregnation successful, but also that the polymeric shell acted as a protective barrier against the effects of oxidation from the surrounding environment, nearly $99 \%$ of total iron content was in the form of zero-valent iron. When applied towards the remediation of two common water contaminants, nitrobenzene and nitrate, the composite material exploited the qualities of both the activated carbon and the polymeric network to work together in a synergistic manner. In that the increased protection from oxidation allowed for increased reactivity of the nanoscale zero-valent iron, and that the adsorption abilities of both the carbon and the polymer achieved a higher amount of total removal of the contaminants.
\end{abstract}

Keywords: activated carbon, nZVI, covalent organic polymers, water treatment, iron impregnation 


\section{INTRODUCTION}

In order for societies and populations to continue to grow sustainably, the availability of potable water is most often the limiting factor, especially for developing nations. Even in more developed countries, the increased strain on the water treatment system from population growth is an ever-increasing problem. Therefore, exploiting new and untapped water sources for drinking water will become a necessary solution for supplying a population with potable water. This will include many sources of groundwater that are, or will be, contaminated with various environmental pollutants. One estimate has stated that there are over 20,000 contaminated groundwater sites in Europe alone, with a further 350,000 that have yet to be identified [1]. Zero-valent iron (ZVI) has become the target of many studies regarding the treatment of various pollutants found in groundwater contaminant plumes, and has seen extensive application for in situ treatment of these plumes in the form of permeable reactive barriers, where the material is injected into the subsurface at a point where the plume can flow through the barriers [2,3]. The use of ZVI is an ideal candidate for treatment technologies, as the element iron is ubiquitously found in the earth's crust, safe for the environment, and is an effective reductant $\left(\mathrm{E}^{0}=-0.44\right.$ V). The chemical degradation mechanism by ZVI involves the direct transfer of electrons to the contaminants, transforming them into non-toxic, less toxic, or more readily biodegradable species [4,5]. A wide variety of pollutants, including halogenated organics, nitro-aromatics, heavy metals, and oxy-anions, have been successfully remediated by utilizing the reduction reaction mechanism of ZVI [6]. In particular, ZVI has often been demonstrated to be effective towards two model water contaminants commonly found in the subsurface, the aromatic compound nitrobenzene and the inorganic compound nitrate; both of which are assessed in this study. Nitrobenzene was chosen, as it is a contaminant of emerging concern [7] and that ZVI has already been reported to effectively degrade nitrobenzene to aniline in the following reaction [8-10]:

$$
3 \mathrm{Fe}^{0}+\mathrm{C}_{6} \mathrm{H}_{5} \mathrm{NO}_{2}+6 \mathrm{H}^{+} \rightarrow 3 \mathrm{Fe}^{2+}+\mathrm{C}_{6} \mathrm{H}_{5} \mathrm{NH}_{2}+2 \mathrm{H}_{2} \mathrm{O}
$$


Nitrate was chosen, as it has been recognized as a common source of contamination in groundwater for some time [11] and that ZVI has already been reported to degrade nitrate to ammonia in the following reaction [12,13]:

$$
4 \mathrm{Fe}^{0}+\mathrm{NO}_{3}^{-}+10 \mathrm{H}^{+} \rightarrow 4 \mathrm{Fe}^{2+}+\mathrm{NH}_{4}^{+}+3 \mathrm{H}_{2} \mathrm{O}
$$

And, more recently, synthesis of ZVI on the nanoscale (nZVI) has quickly gained traction, due to the substantially increased surface area as the particle size decreases, from $0.15 \mathrm{~m}^{2} / \mathrm{g}$ in commercially available microscale ZVI to $17 \mathrm{~m}^{2} / \mathrm{g}$ in nZVI used in a recent study [14]. This increase in surface area can enhance the interactions, and subsequent reactivity, between the iron surface and the contaminant. However, this increased reactivity comes at a cost, as it can create general particle instability, rapid aggregation, and also allow for faster loss of reactivity coming from the interactions with components in the surrounding environment (i.e. dissolved oxygen, anions, natural organic matter, etc.) $[15,16]$; all of which subsequently will cause issues when separating the nZVI from the treated water [17]. Because of this problem, the use of nZVI in the form of ex situ operations, i.e. pump-and-treat, may be a more practical use of nZVI; as it is that the treatment conditions can be more easily controlled. These type of pump-and-treat and other ex situ operations are quite common-place for contaminant adsorption by materials like activated carbon, and usually come in the form of columns or packed-bed containers [18].

Activated carbon, used in powdered or granular form (GAC), has often been cited as the most prolific and widespread material used in the treatment of all types of water sources [19]. In fact, various low-tech versions of carbon, such as charcoal, have been used for environmental remediation since the $18^{\text {th }}$ century [20]. Treatment targets for activated carbon span a vast range of contaminants, from pesticides [21], to pharmaceuticals and endocrine disrupting compounds [22], to heavy metals [23], to inorganic ions [24], and many others. However, although the adsorption mechanism found in activated carbon is extremely effective, this does not solve the problem of degrading the contaminant of concern to a more benign species. Hence, the disposal/regeneration of 
the contaminant loaded activated carbon is an issue. This can be addressed by incorporating a reactive and environmentally safe material, such as nZVI, into the matrix of the activated carbon. In doing so, it is possible to simultaneously adsorb contaminants and allow for subsequent degradation of the compound. Various attempts at combining carbon materials with nZVI for the purpose of environmental remediation have been made in the past. Some of these synthesis methods include a thermal route for carbon supported nZVI [25], preparation of colloidal carbo-iron composites [26], and an aerosol-based method for iron-carbon nanocomposites [27]. In a previous study, it was determined that immobilizing nZVI particles into the matrices of nanoporous covalent organic polymers (COPs) can vastly improve the stability of nZVI, while still allowing for contaminant removal [28]. These frameworks of COPs are extremely robust, even in extreme conditions such as being subjected to repeated $\mathrm{CO}_{2}$ adsorption/desorption tests at high temperatures $120^{\circ} \mathrm{C}$ [29] or immersion in boiling water for weeks at a time [30]; and, in addition to groundwater remediation [28], have already been proven to be effective in other environmental applications, such as carbon dioxide capture [30,31] and solvent uptake [32]. Therefore, in order to combine all three of these technologies (i.e. GAC, nZVI, and COPs), a synthesis strategy was developed to chemically graft COPs to the surface of GAC [33], whereupon nZVI could then be impregnated into the GAC-COP matrix. This allows for the use of an active and cheap back-bone material that can also utilize the nanoporous nature of COPs and the reductive degradation ability of nZVI.

Herein, we successfully developed a composite material of GAC with grafted COP, specifically COP-19 [29], (GAC-COP) and proceeded to impregnate GAC-COP with nZVI particles (GAC-COP-Fe). This COP grafting procedure improved upon the previously developed procedure [33], in that it is now an easier-to-perform and more environmentally friendly method. Specifically, this was achieved by lowering the synthesis temperatures and reducing the concentrations of certain harmful reagents. Following the grafting of COP to GAC, ferrous iron was impregnated into the pores of the GAC-COP matrix, where it is ultimately reduced from $\mathrm{Fe}^{2+}$ to $\mathrm{Fe}^{0}$ via in situ chemical reduction with sodium borohydride $\left(\mathrm{NaBH}_{4}\right)$. This is the latest step in the advancement of GAC and COP technology; to not only include iron, but rather reactive iron, into the composite matrix. A major 
hindrance to the use of nZVI is the aggregation of the particles, stemming from van der Waals and magnetic attraction forces [34,35]. Given that different COPs have been used to stabilize nZVI in the past [28], this new material with impregnated nZVI hinders that from occurring, by physically caging nZVI particles into the pores of the COP and GAC. This also allows for further separation and isolation of nZVI from itself and preventing aggregation, as it is that each individual granule can be considered its own island of a reaction vessel. Furthermore, the reactivity of the nZVI was confirmed using degradation tests towards the reduction of both nitrobenzene and nitrate. These new composite materials create a unique treatment technique, where using the advantages of physical adsorption and chemical degradation can be utilized concurrently in symbiosis.

\section{MATERIALS AND METHODS}

\subsection{Chemicals}

Activated carbon (GAC, granular) was obtained from Samchun Chemical Co. (Pyeongtaek, Gyeonggi-do, Republic of Korea). Acetic acid $\left(\mathrm{CH}_{3} \mathrm{COOH}, 99 \%\right)$, acetone $\left(\mathrm{C}_{3} \mathrm{H}_{6} \mathrm{O}, 99 \%\right)$, aniline $\left(\mathrm{C}_{6} \mathrm{H}_{5} \mathrm{NH}_{2}, 99 \%\right)$, dichloromethane $\left(\mathrm{CH}_{2} \mathrm{Cl}_{2}, 99 \%\right)$, dimethyl sulfoxide (DMSO, $\left(\mathrm{CH}_{3}\right)_{2} \mathrm{SO}$, 99\%), ethanol $\left(\mathrm{C}_{2} \mathrm{H}_{6} \mathrm{O}, 96 \%\right)$, hydrochloric acid $(\mathrm{HCl}, 37 \%)$, iron (II) sulphate heptahydrate $\left(\mathrm{FeSO}_{4} \cdot 7 \mathrm{H}_{2} \mathrm{O}, 99 \%\right)$, melamine $\left(\mathrm{C}_{3} \mathrm{H}_{6} \mathrm{~N}_{6}, 99 \%\right)$, N,N-diisopropylethylamine (DIPEA, 99.0\%), nitric acid $\left(\mathrm{HNO}_{3}, 60 \%\right)$, nitrobenzene $\left(\mathrm{C}_{6} \mathrm{H}_{5} \mathrm{NO}_{2}, 99 \%\right)$, polyethylene glycol 400 (PEG), sodium borohydride $\left(\mathrm{NaBH}_{4}, 99 \%\right)$, sodium nitrate $\left(\mathrm{NaNO}_{3}, 99 \%\right)$, sulfuric acid $\left(\mathrm{H}_{2} \mathrm{SO}_{4}, 47 \%\right)$, terephthaldehyde $(99 \%)$, and thionyl chloride $\left(\mathrm{SOCl}_{2}, 99 \%\right)$ were obtained from Sigma-Aldrich (St. Louis, MO, USA). All chemicals were used, as obtained, from the supplier.

\subsection{Physical Characterization}

Thermo-gravimetric analysis (TGA), Discovery TGA, TA Instruments, USA) was employed to evaluate the thermal stability and robustness of the materials, and coupled with Fourier-transform infrared spectroscopy (TGA-IR, Nicolet iS10, Thermo Scientific, USA) to determine the functional groups degassed off samples during analysis. Surface characterization and elemental composition was performed using X-ray photoelectron 
spectroscopy (XPS, K-Alpha, Thermo Scientific, USA) and analyzed under vacuum with a monochromated Al$\mathrm{K} \alpha \mathrm{X}$-ray source (photon energy $=1486.7 \mathrm{eV}$ ) and an X-ray spot size of $400 \mu \mathrm{m}$. Ion etching during XPS analysis was performed with a tunable beam of argon ions to sputter off the surface and expose deeper layers. Surface imaging of the activated carbon granules and morphological observation of the polymer shell found on the granules was performed using scanning electron microscopy (SEM, Quanta FEG 200 ESEM, FEI, The Netherlands). Elemental identification and mapping of the SEM images was produced using energy-dispersive X-ray spectroscopy (EDS) within the instrument, and analyzed with AZtec EDS software (Oxford Instruments, United Kingdom). Content of total iron contained in the samples was determined by atomic absorption spectroscopy (AAS, AAnalyst 200, Perkin Elmer, USA). Samples for AAS were prepared using a previously reported method using acid digestion with nitric acid [28]. Content of reactive iron $\left(\mathrm{Fe}^{0}\right)$ contained within the GAC-Fe and GAC-COP-Fe was determined by measuring the hydrogen $\left(\mathrm{H}_{2}\right)$ gas production via acid digestion, as described in a previous study that evaluated nZVI stabilized with a magnesium aminoclay [36]. As outlined in Eq. 3, it is assumed that with this method, $\mathrm{Fe}^{0}$ is the only species present in the samples capable of producing hydrogen.

$$
2 \mathrm{Fe}^{0}+6 \mathrm{H}^{+} \rightarrow 2 \mathrm{Fe}^{3+}+3 \mathrm{H}_{2} \uparrow
$$

The amount of $\mathrm{Fe}^{0}$ was calculated from the produced hydrogen and measured by gas chromatography (GC, Mikrolab GC82, Mikrolab Aarhus A/S, Denmark). This amount of $\mathrm{Fe}^{0}$ was compared with total iron content, measured by AAS.

\subsection{Preparation of GAC-COP}

Attachment of the polymer shell to the GAC was conducted similarly to a previously reported method [33]. The grafting process consisted of a four-step synthesis procedure, acid oxidation of GAC (Step 1), acyl chlorination (Step 2), melamine attachment (Step 3), and COP attachment (Step 4). Step 1 oxidized $15 \mathrm{~g}$ of GAC with 150 
$\mathrm{mL}$ of a 3:1 mixture of $\mathrm{HNO}_{3}(30 \%)$ and $\mathrm{H}_{2} \mathrm{SO}_{4}(47 \%)$ for $24 \mathrm{~h}$ at $25^{\circ} \mathrm{C}$, forming carboxylic groups on the carbon surface (GAC-Ox). GAC-Ox was washed with copious amounts of Milli-Q deionized water until the rinsate reached a neutral $\mathrm{pH}$ and then dried for $12 \mathrm{~h}$ at $110^{\circ} \mathrm{C}$ in a vacuum oven. Step 2 converted the carboxylic groups to acyl chloride groups by reacting $10 \mathrm{~g}$ of GAC-Ox with $250 \mathrm{~mL}$ of a $4: 1$ mixture of dichloromethane and $\mathrm{SOCl}_{2}$ for $24 \mathrm{~h}$ at $35^{\circ} \mathrm{C}$ under reflux in a $\mathrm{N}_{2}$ atmosphere (GAC-Acyl). GAC-Acyl was immediately dried via rotary evaporation at $40^{\circ} \mathrm{C}$ and 300-400 mbar of vacuum to remove all solvents. Step 3 substituted melamine on to the acyl chloride group by reacting $10 \mathrm{~g}$ of GAC-Acyl with $1000 \mathrm{mg}$ of melamine in a $250 \mathrm{~mL}$ solution of DMSO and $5 \mathrm{~mL}$ of DIPEA that had been sonicated until complete dissolution had taken place; this solution reacted for $24 \mathrm{~h}$ at $110^{\circ} \mathrm{C}$ in a $\mathrm{N}_{2}$ atmosphere (GAC-Mel). After filtration, GAC-Mel was washed thoroughly three times each with DMSO, MilliQ deionized water, and ethanol; then dried for $12 \mathrm{~h}$ at $110^{\circ}$ $\mathrm{C}$ in a vacuum oven. Step 4 performed the final attachment of COP-19 to GAC, by building the polymeric network off of the amine groups stemming from the attached melamine, following a similar strategy to previously reported methods for polymer construction utilizing Schiff base chemistry with melamine and terephthaldehyde as the core monomers [29,37]. This was accomplished by reacting $8 \mathrm{~g}$ of GAC-Mel with 1000 $\mathrm{mg}$ of terephthaldehyde and $625 \mathrm{mg}$ of melamine in $250 \mathrm{~mL}$ of DMSO for $72 \mathrm{~h}$ at $155^{\circ} \mathrm{C}$ in a $\mathrm{N}_{2}$ atmosphere (GAC-COP). In order to remove any residuals, after filtration GAC-COP particles were washed vigorously three times each with DMSO, then acetone, then MilliQ deionized water, and finally ethanol; particles were then dried in a vacuum oven for $12 \mathrm{~h}$ at $110{ }^{\circ} \mathrm{C}$. Figure 1 identifies the entire series of reaction schemes.

Figure 1: Schematic representation of the COP-19 grafting process to the GAC (illustrated by large gray object, not to scale).

Weighing of the before and after products was done in order to determine the mass fraction of the COP material grafted to the GAC. The bulk sample measurement indicated that the mass fraction of COP in GAC-COP was approximately $17 \%(\mathrm{~m} / \mathrm{m})$. 


\section{4 nZVI impregnation into GAC and GAC-COP}

As supplied GAC and as prepared GAC-COP were used as the matrices for impregnating nZVI. Impregnation of nZVI into both GAC and GAC-COP was conducted in a $200 \mathrm{~mL}$ three-neck round bottom flask reactor by submerging GAC or GAC-COP into a ferrous iron solution. The ferrous iron solution was prepared as a mixture of $28 \mathrm{~g}$ of $\mathrm{FeSO}_{4} \cdot 7 \mathrm{H}_{2} \mathrm{O}$ and $2 \mathrm{~g}$ of PEG in $120 \mathrm{~mL}$ of MilliQ deionized water. Once a homogeneous solution was achieved, $8 \mathrm{~g}$ of GAC or GAC-COP was added to the solution. The solution was continuously mixed for 12 $\mathrm{h}$ via mechanical stirring at $50 \mathrm{RPM}$ with a $\mathrm{N}_{2}$ atmosphere. Afterwards, the remaining solution in the three-neck flask was discarded. Then, $80 \mathrm{~mL}$ of fresh $\mathrm{N}_{2}$-purged (to remove dissolved oxygen) MilliQ deionized was added to the flask, whereupon the atmosphere inside the flask was restored to a $\mathrm{N}_{2}$ environment. Once free of ambient air, $40 \mathrm{~mL}$ of $\mathrm{NaBH}_{4}$ in MilliQ deionized water $(3.58 \mathrm{M})$ solution was injected via peristaltic pump at a flow rate of $5 \mathrm{~mL} / \mathrm{min}$. The mixture was continuously stirred for $30 \mathrm{~min}$ after complete injection of $\mathrm{NaBH}_{4}$ into the flask, to provide enough time for total formation of nZVI. The drop-wise addition of $\mathrm{NaBH}_{4}$ to ferrous sulfate reduces the iron to its zero-valent state in the following reaction:

$$
2 \mathrm{Fe}^{2+}+\mathrm{BH}_{4}^{-}+3 \mathrm{H}_{2} \mathrm{O} \rightarrow 2 \mathrm{Fe}^{0}+\mathrm{H}_{2} \mathrm{BO}_{3}^{-}+4 \mathrm{H}^{+}+2 \mathrm{H}_{2}
$$

Prepared nZVI impregnated within GAC (GAC-Fe) and GAC-COP (GAC-COP-Fe) was washed with ethanol to remove residual molecules leftover from the synthesis procedure. Subsequently, the material was allowed to dry in a vacuum oven at $60^{\circ} \mathrm{C}$ for $4 \mathrm{~h}$. Dried sample material was stored in air tight vials inside an anaerobic chamber until used for characterization or reactivity testing.

\subsection{Reactivity and adsorption tests}

Batch tests for reactivity of the prepared materials were conducted in $25 \mathrm{~mL}$ glass serum vials. The desired amount of GAC-Fe or GAC-COP-Fe (i.e. $1 \mathrm{~g}$ ) was weighed into reaction vials inside an anaerobic chamber, and the vials were filled with $19 \mathrm{~mL}$ of MilliQ deionized water and $0.5 \mathrm{~mL}$ of acetic acid solution (initial 
concentration $=40 \mu \mathrm{M}, \mathrm{pH}=4.5$ ), then securely capped with a PTFE/silicon septum and an aluminum crimp seal. Each vial was injected with $0.5 \mathrm{~mL}$ of the desired stock contaminant solution, through the septum, in order to initiate the reaction. The $\mathrm{pH}$ was measured throughout each experiment and consistently remained between 4.5 and 4.75 .

The batch tests were designed to simultaneously determine the reduction activity of nZVI and adsorption capacity of GAC-Fe and GAC-COP-Fe. Each substrate and its reduction product (i.e. nitrobenzene and aniline [8-10], nitrate and ammonia [12,13], Eqs. 1,2) were injected into separate reaction vials with either the GAC-Fe or GAC-COP-Fe sample, so that a mass balance of the substrate and its corresponding reduction product could be acquired. Nominal concentrations of nitrobenzene, aniline, nitrate as nitrogen $\left(\mathrm{NO}_{3}-\mathrm{N}\right)$, and ammonium as nitrogen $\left(\mathrm{NH}_{4}-\mathrm{N}\right)$ were $500 \mu \mathrm{M}, 500 \mu \mathrm{M}, 25 \mathrm{mg}-\mathrm{N} / \mathrm{L}$, and $25 \mathrm{mg}-\mathrm{N} / \mathrm{L}$, respectively. Reaction vials were mixed on an orbital shaker throughout the entire reaction period, in order to maintain a homogeneous mixture. Samples of $2 \mathrm{~mL}$ were taken periodically and filtered with $0.45 \mu \mathrm{m}$ syringe filters (Minisart RC25, regenerated cellulose, Sartorius AG, Germany); the concentration of reaction products in the samples were then measured using the colorimetric assay developed in a previous study [38]. Reaction kinetics were subsequently interpreted by pseudo first-order kinetics:

$$
C_{t}=C_{0} \times e^{-k t}
$$

Where, $C_{t}$ is the concentration $(\mu M$ or $\mathrm{mg}-\mathrm{N} / \mathrm{L})$ at time, $\mathrm{t}(\mathrm{min}), \mathrm{C}_{0}$ is the initial concentration $(\mu \mathrm{M}$ or $\mathrm{mg}-\mathrm{N} / \mathrm{L})$, and $\mathrm{k}$ is the reaction rate in terms of $\min ^{-1}$.

\section{RESULTS AND DISCUSSION}

\subsection{Properties of materials}

\subsubsection{TGA and TGA-IR analyses}


Thermo-gravimetric analysis (TGA) was employed to quantify the thermal stability and robustness of the materials; and the off-gas stream was further coupled with Fourier-transform infrared spectroscopy (TGA-IR) to determine the functional groups present in the GAC-COP material. During TGA analysis, up to $800{ }^{\circ} \mathrm{C}$, the raw GAC material had a total mass loss of approximately $12.0 \%$, which was also observed before in the precursory study [33] and is due to the inherent impurities of this particular type of carbon; while the GAC-COP materials had a total mass loss of approximately $30.2 \%$ (Figure $2 \mathrm{~A}$ ). The mass loss difference here being approximately $18.2 \%$, slightly higher than the $17 \%$ measured by bulk sample weighing.

Figure 2: A) TGA analysis for GAC (black, dashed line) and GAC-COP (red, solid line); and B) TGA-IR spectra for GAC-COP progressing from ambient $38^{\circ} \mathrm{C}$ (blue, bottom line) to $800{ }^{\circ} \mathrm{C}$ (red, top line).

Using TGA-IR, indication that the added material present in GAC-COP was in fact the expected polymer grafted to $\mathrm{GAC}$ was assessed (Figure 2B). Initially, at the ambient instrument analysis temperature (i.e. $38{ }^{\circ} \mathrm{C}$ ), no discernible peak pattern is found in the spectra of GAC-COP. At $200{ }^{\circ} \mathrm{C}$, a large peak is observed in the1050$1150 \mathrm{~cm}^{-1}$ range, corresponding to $\mathrm{C}-\mathrm{O}$ groups leaving the matrix. More notably, it is apparent that as the temperature is increased, certain peak groups appear and become more pronounced. The peak found at $1650 \mathrm{~cm}^{-}$ ${ }^{1}$ can be attributed to primary amine groups of melamine $\left(\mathrm{NH}_{2}\right.$ deformation) [37]. Hetero-aromatic ring systems were also observed in the bands at $1550 \mathrm{~cm}^{-1}$ and $1480 \mathrm{~cm}^{-1}$, corresponding to quadrant and semicircle stretching of the triazine rings found in the grafted polymer [37]. These particular spectra profiles were in accordance with previous studies describing this polymer [29,37] and utilizing this polymer for water treatment $[28,33]$.

\subsubsection{XPS analysis}

Surface elemental characterization of the various GAC materials was conducted using X-ray photoelectron spectroscopy (XPS). As it is that the analysis and penetration depth of XPS is in the range of 5-10 nm, this was done in order to confirm that the polymer was attached to the surface of the GAC. This was also done to 
determine if iron was impregnated into the matrix of the GAC-COP, as well as to determine the exact speciation of the iron found in the matrix. Outlined in Table 1, the survey analysis using XPS determined that bare GAC (Figure 3A) is primarily carbon, at $92 \%$, and that COP grafted GAC (Figure 3B) contains the elemental profile of the added polymer; in particular the large increase in nitrogen $(\sim 33 \%)$. Finally, following the nZVI impregnation step it was evident that there was iron present in the material.

Table 1. Surface atomic percentages of the different GAC materials, as determined by XPS.

The trend is clear, that the atomic evolution on the surface of the GAC follows the proposed COP attachment mechanism; as well as the existence of iron in the GAC-COP-Fe matrix. However, the final GAC-COP-Fe product contains a small fraction of sodium, which can be explained by any residual leftovers from the $\mathrm{Fe}^{0}$ reduction process using $\mathrm{NaBH}_{4}$. Further analysis into the C1s spectrum using XPS reveals a more detailed look at the bonding structure associated with carbon. In the bare GAC, it is evident, as expected, that the surface is primarily carbon with a small amount of oxidation indicated by the presence of a small C-O peak (Figure 3C). Analyzing the C1s (Figure 3D) spectra for GAC-COP reveals the complex nature of the polymer attached to the surface, including the major peak of $\mathrm{C}-\mathrm{N}(287.9 \mathrm{eV})$ and the minor peaks of $\mathrm{C}=\mathrm{O}(289.2 \mathrm{eV}), \mathrm{C}-\mathrm{O}(286.4 \mathrm{eV})$, and $\mathrm{C}-\mathrm{NH}_{2}(285.4 \mathrm{eV})$.

Figure 3: X-ray photoelectron spectroscopy data for: A) Bare GAC survey scan; B) GAC-COP survey scan; C) C1s scan for bare GAC; and D) C1s scan for GAC-COP.

Further elucidation into the structure of the COP attachment is achieved using the XPS instrument to perform consecutive ion etchings off the surface of the granule. Although determination of the exact amount of material removed during each etching is unknown due to the extreme sensitivity of the process to the interactions between the surface composition, etch-rate, and ion-gun; ion beam etchings, followed by characterization at each 
level, provide a depth profile of the material. This etching and characterization technique was employed on the final GAC-COP-Fe material. The evolution of the C1s spectra (Figure 4A) through each etching event outlines a progressive change in the complex polymer-based peak structure from that observed in Figure $3 \mathrm{D}$ to the primarily single carbon peak structure observed in Figure 3C. Greater insight into the nature of the iron speciation found in the final composite is observed in the Fe2p spectra (Figure 4B). Of particular interest is the progressive build-up of the two major $\mathrm{Fe}^{0}$ peaks and the slow diminishing of various other iron oxide peaks, as more ion etchings are performed. These various Fe2p peaks were confirmed by comparison with a previous study focusing on XPS analysis of ZVI [39].

Figure 4: X-ray photoelectron spectroscopy data for: A) depth profile ion etched C1s scan for GAC-COP-Fe (note that the $\mathrm{x}$-axis has been reversed to better display peak variation); B) depth profile ion etched Fe2p scan for GAC-COP-Fe; C) peak deconvolution of C1s scan etch-0 (before etchings) in plot A; and D) peak deconvolution of Fe2p scan etch-9 (after final etching) in plot B.

Although surface oxidation is inevitable during sample preparation, it should be noted that the nanoporous structure of the COP material on the GAC is protecting the iron from the oxidation effects of the surrounding environment, allowing for increased reactivity and shelf-life of the ZVI. This phenomenon was also previously observed in a similar study impregnating nZVI into various COPs [28]. Not only did the speciation of iron change with increasing depth, the percentage of iron with respect to the other elements present also increased. In the bare GAC, the iron content was approximately $1.2 \%$ (Table 1), and after the ion etchings were complete, the iron content had increased to approximately $3.3 \%$.

\subsubsection{SEM analysis}

Visual evidence of the successful attachment of COP to the surface of the GAC was gathered using scanning electron microscopy (SEM). The structure of the bare GAC (Figure 5A) reveals the amorphous porous nature of 
the granules, inherent in all activated carbons. Following the grafting of COP onto the surface of the GAC, it is apparent that there has been a polymer shell grafted to the surface (Figure 5B), as it is that the larger pores of the activated carbon are filled in with the nanoporous polymer material. When images at higher magnification are obtained for bare GAC (Figure 5C) and GAC-COP-Fe (Figure 5D), it is easier to see that the surface has been coated and filled in with the polymeric network. For comparison, imaging of GAC-Fe (Figure 5E) reveals a similar barren amorphous landscape to bare GAC, but with loosely bound clusters of nZVI scattered across the surface. Clusters of nZVI found in GAC-COP-Fe were physically observed under higher magnification (Figure 5F) that are typical of nZVI clustering into chain-like formations. Ultimately, further elucidation is achieved after the impregnation of iron when using energy-dispersive X-ray spectroscopy (EDS) coupled with the SEM imaging. Figure $5 \mathrm{G}$ and $5 \mathrm{H}$ give images of identical areas of a GAC-COP-Fe granule, $5 \mathrm{G}$ bearing the raw SEM electron image and $5 \mathrm{H}$ bearing the corresponding SEM-EDS iron mapping image. It can be determined from the SEM-EDS that there are clusters and regions of iron (colored in yellow) distributed, albeit unevenly, over the entire granule surface. The lack of uniformity in iron distribution on the GAC surface is inherently a natural phenomenon in the process of iron impregnation, due to the susceptibility of nZVI to inter-particle attractive forces [34,35]; and, this has also been obseryed before when impregnating nZVI onto/into GAC [40].

Figure 5: Scanning electron microscopy images of: A) bare GAC at low magnification; B) GAC-COP-Fe at low magnification; C) bare GAC at high magnification D) GAC-COP-Fe at high magnification; E) GAC-Fe at high magnification; F) nZVI clusters contained within the GAC-COP-Fe matrix; G) SEM-EDS analysis electron image of GAC-COP-Fe; and H) corresponding SEM-EDS analysis iron mapping image of Figure-5G.

\subsubsection{Reactive iron content}

The total amount of iron found in the samples was determined by acid digestion, followed by analysis with atomic absorption spectroscopy (AAS). Results for the amount of iron found in GAC-Fe were comparable to previously reported numbers from a study also attaching nZVI to GAC with similar size distributions [41]. 
However, the total iron content, as determined by AAS, decreased when after in situ reduction of ferrous iron to nZVI within the GAC-COP matrix (GAC-COP-Fe), from approximately $17 \mathrm{mg}-\mathrm{Fe} / \mathrm{g}-\mathrm{GAC}$ to $9 \mathrm{mg}-\mathrm{Fe} / \mathrm{g}-\mathrm{GAC}$. This loss in total iron percentage can be explained due to the added mass of the COP shell grafted to the GAC surface, as well as the smaller pore sizes of the COP material inhibiting more mass transfer of iron into the composite matrix. Although, the trend was opposite when measuring the hydrogen gas production (Eq. 3). Under controlled anaerobic conditions during measurement, in order to prevent any external oxidation, the zerovalent content (i.e. $\mathrm{Fe}^{0}$ compared to Fe-total) of the iron in GAC-Fe was approximately $80.2 \%$, while the zerovalent content of the iron in GAC-COP-Fe was nearly perfect, at approximately $98.2 \%$. From these results, it is apparent that the grafted COP material creates conditions where the nZVI is more protected from the surrounding environment, in terms of susceptibility to oxidation. Correspondingly, using the same hydrogen gas production method to determine reactive iron, another study applying nZVI particles to dechlorinate trichloroethylene found that freshly lab-synthesized nZVI and commercially available nZVI contained $92 \%$ and $52 \%$ reactive iron, respectively [42]. Moreover, the fact that the reactive iron content increased when supported on GAC-COP is a major advantage, since often times, stabilizing nZVI with a support material does not also correlate to benefiting the reactive iron content [43]. This is a breakthrough in the applicability of nZVI for contaminant degradation, in that the composite GAC-COP-Fe is protecting the nZVI from oxygen and other oxidative constituents in the surrounding environment; while, as is discussed later in the text, still maintaining reactivity with waterborne contaminants. Full application of nZVI is largely dependent on combatting the negative effects of oxygen and complexing agents in the surrounding environment [6]; and, the added benefits of creating an oxidation-shielding composite will result in a material better suited for real-world implementation.

\subsection{Nitrobenzene and nitrate reduction}

For comparative purposes and to see the effect that the COP shell has when degrading and removing nitrobenzene, composites of GAC-Fe and GAC-COP-Fe were tested. Furthermore, for each composite, a control test was performed to assess the aniline adsorption capacity. After four hours, the GAC-Fe proved to be capable 
of adsorbing $233 \mu \mathrm{M}$ of aniline (46.7\% of original aniline concentration); while it was also able to produce at least $283 \mu \mathrm{M}$ of aniline (56.6\% of original nitrobenzene concentration) before adsorption was the only significant removal mechanism remaining (Figure 6A). Concurrently, after four hours, the GAC-COP-Fe proved to be capable of adsorbing $471 \mu \mathrm{M}$ of aniline (94.2\% of original aniline concentration); while it also was able to produce at least $318 \mu \mathrm{M}$ of aniline (63.6\% of original nitrobenzene concentration) before adsorption was the only significant removal mechanism remaining (Figure 6B). Assuming the sum of the adsorbed aniline in the control test (Figure 6A,B; red lines) and the produced aniline in the reactivity test (Figure 6A,B; blue lines) is the total amount of degraded nitrobenzene, and using pseudo first-order kinetics (Eq. 5), reaction curves were plotted and calculated rate constants were 0.0702 and $0.2212 \mathrm{~min}^{-1}$ for GAC-Fe and GAC-COP-Fe, respectively (Figure 6C). It can therefore be inferred that once both lines converge, the reduction of nitrobenzene to aniline is essentially over and the remaining operating mechanism is adsorption. GAC-COP-Fe exhibited not only higher total removal of nitrobenzene, but also higher aniline adsorption and faster reaction kinetics; outperforming similar materials using nZVI supported on carbon [9]. The faster reaction kinetics, especially in the first 15 minutes, are most likely due to the higher fraction of ZVI compared with total iron. These tests also reveal an interesting occurrence, in that GAC-COP-Fe exhibits an extremely larger capacity for nitrobenzene and aniline adsorption than GAC-Fe. Although somewhat controversial in the past [44], the most likely explanation of increased adsorption is due to the phenomenon of pi-pi stacking between the different aromatic components of the COP material and the nitrobenzene and/or aniline, of which similar occurrences have been observed or synthesized before [45-47]. Therefore, exact quantification of nitrobenzene becomes difficult, but we assume that the sum of produced aniline and adsorbed aniline can be the maximum amount of nitrobenzene reduction (Figure 6C). The synergistic effects of the adsorption capacity of the GAC-COP and the degradation capability of the nZVI make this a very effective material for environmental remediation.

Figure 6: Nitrobenzene-reduction/aniline-adsorption batch tests, A) aniline adsorption control experiment (red) and nitrobenzene reduction experiment (blue) by GAC-Fe; B) aniline adsorption control experiment (red) and 
nitrobenzene reduction experiment (blue) by GAC-COP-Fe; and C) reaction kinetics using Eq. 5, in terms of aniline concentration, of GAC-Fe (blue, from Fig. 6A) and GAC-COP-Fe (red, from Fig. 6B).

As with the assessment with nitrobenzene, for comparitive purposes, and to see the effect that the COP shell has when degrading and removing nitrate, composites of GAC-Fe and GAC-COP-Fe were tested. Again, for each composite, a control test was performed to assess the ammonia adsorption capacity. After four hours, the GACFe proved to be capable of adsorbing $12.2 \mathrm{mg}-\mathrm{N} / \mathrm{L}$ of ammonia (48.8\% of original ammonia concentration); while it also was able to produce at least $11.6 \mathrm{mg}-\mathrm{N} / \mathrm{L}$ of ammonia (46.4 \% of original nitrate concentration) before adsorption was the only significant removal mechanism remaining (Figure 7A). Concurrently, after four hours the GAC-COP-Fe proved to be capable of adsorbing $20.0 \mathrm{mg}-\mathrm{N} / \mathrm{L}$ of ammonia $(79.9 \%$ of original ammonia concentration); while it also was able to produce at least $6.3 \mathrm{mg}-\mathrm{N} / \mathrm{L}$ of ammonia (25.2 \% of original nitrate concentration) before adsorption was the only significant removal mechanism remaining (Figure 7B). Assuming the sum of the adsorbed ammonia in the control test (Figure 7A,B; red lines) and the produced ammonia in the reactivity test (Figure 7A,B; blue lines) is the total amount of degraded nitrate, and using pseudo first-order kinetics (Eq. 5), reaction curves were plotted and calculated rate constants were 0.04611 and 0.04541 $\min ^{-1}$ for GAC-Fe and GAC-COP-Fe, respectively (Figure 7C). Again here, it can also be inferred that once both lines converge, the reduction of nitrate to ammonia is essentially over and the remaining operating mechanism is adsorption. Overall, the degradation and removal of contaminants was more effective with GACCOP-Fe; and that the degradation and removal by GAC-COP-Fe favors aromatic contaminants due to the effect of pi-pi stacking of the aromatic compound to the COP material. As previously discussed, the attached polymer has a natural affinity towards aromatic compounds, due to the phenomenon of pi-pi stacking; which is most likely the explanation for the lower removal kinetics of nitrate by GAC-COP-Fe. Although not as pronounced as with nitrobenzene, nitrate removal is apparent. The degradation and removal of nitrate is not hindered by the polymeric network itself; giving rise to the fact that the polymeric network demonstrates obvious benefits for aromatics like nitrobenzene, while not losing any ability in the capacity to remove simple inorganic compounds 
like nitrate. The most likely reasoning for this is the known affinity of nitrate coordination in imine-linked compounds $[48,49]$, as it is that the COP-19 grafted to GAC also contains these imine linkages. Furthermore, these same studies $[48,49]$ also demonstrate the complexation of iron and other metal ions to imine-linked compounds; this may also occur with the grafted polymer here, further enhancing iron impregnation and subsequent nZVI formation.

Figure 7: Nitrate-reduction/ammonia-adsorption batch tests, A) ammonia adsorption control experiment (red) and nitrate reduction experiment (blue) by GAC-Fe; B) ammonia adsorption control experiment (red) and nitrate reduction experiment (blue) by $\mathrm{GAC}-\mathrm{COP}-\mathrm{Fe}$; and $\mathrm{C}$ ) reaction kinetics using Eq. 5, in terms of ammonia concentration, of GAC-Fe (blue, from Fig. 7A) and GAC-COP-Fe (red, from Fig. 7B).

\section{CONCLUSIONS}

In this study, covalent organic polymer (COP) was grafted to the surface of granular activated carbon (GAC), which was confirmed using TGA-IR analysis, XPS analysis, and SEM imaging. Subsequently, nano-iron was loaded into the porous structure of the GAC-COP, as well as bare GAC, for reference. These impregnated iron particles were then reduced to their zero-valent state via in situ chemical reduction, which was confirmed by atomic absorption spectroscopy (AAS) for the total iron content, and by $\mathrm{H}_{2}$ gas production via acid digestion for ZVI content. Further analysis with XPS, using a depth profile technique, revealed two very interesting profiles. First, the shift in grafted COP on the surface on the surface of the granules to pure carbon towards the core of the granules; and second, that the iron content not only increased with increasing depth into the granules, but also that the speciation of iron gradually transitioned from slightly oxidized at the surface to dominantly zero-valent with increasing depth. The porous nature of the COP material grafted to the surface proved to act as a means for entrapment of the nZVI; as well as act as a protective barrier against oxidation, evident from the iron being nearly $100 \%$ zero-valent in the GAC-COP-Fe granules. This then led to improved removal, in terms of adsorption and degradation, of nitrobenzene and to a lesser extent nitrate. Although, adsorption of nitrobenzene 
and aniline to the COP via pi-pi stacking interfered with detection of nitrobenzene adsorption, reaction kinetics were much higher with GAC-COP-Fe vs. GAC-Fe. Ultimately, it was determined that grafting nanoporous polymers to GAC can not only protect nZVI from oxidation, but also leads to increased reaction and removal kinetics of contaminants in water. Due to their physico-chemical properties, including contaminant reactivity and optimal granule size, these materials are very promising candidates for the application into flow-through column or packed-bed container water treatment systems.

\section{Acknowledgements}

P.D.M., B.U., M.H.J., and H.R.A. acknowledge funding for this study from the Technical University of Denmark (DTU) through the KAIST-DTU Signature Project on Integrated Water Technology. D.T. and C.T. Yavuz acknowledge the financial support by the Basic Science Research Program through the National Research Foundation of Korea (NRF), ICT \& Future Planning (2013R1A1A1012998), and IWT (NRF-2012-C1AAA001M1A2A2026588). Y.H. acknowledges financial support by the National Research Foundation of Korea (NRF) grant funded by the Korea government (MSIP; Ministry of Science, ICT, \& Future Planning) (No. NRF2017R1C1B5015387) and the R\&D Convergence Program of the National Research Council of Science \& Technology (NST) of the Republic of Korea.

\section{References}

[1] G. Prokop, M. Schamann, I. Edelgaard, A.R. Gentile, Management of contaminated sites in Western Europe, European Environment Agency, Copenhagen, Denmark, 2000.

[2] P.G. Tratnyek, T.L. Johnson, M.M. Scherer, G.R. Eykholt, Remediating ground water with zero-valent metals: Chemical considerations in barrier design, Gr. Water Monit. Remediat. 17 (1997) 108-114.

[3] S. Comba, A. Molfetta, R. Sethi, A Comparison Between Field Applications of Nano-, Micro-, and Millimetric Zero-Valent Iron for the Remediation of Contaminated Aquifers, Water, Air, Soil Pollut. 215 
(2010) 595-607. doi:10.1007/s11270-010-0502-1.

[4] T. Tosco, M. Petrangeli Papini, C. Cruz Viggi, R. Sethi, Nanoscale zerovalent iron particles for groundwater remediation: a review, J. Clean. Prod. 77 (2014) 10-21. doi:10.1016/j.jclepro.2013.12.026.

[5] T. Raychoudhury, T. Scheytt, Potential of zerovalent iron nanoparticles for remediation of environmental organic contaminants in water: a review, Water Sci. Technol. 68 (2013) 1425. doi:10.2166/wst.2013.358.

[6] R.A. Crane, T.B. Scott, Nanoscale zero-valent iron: future prospects for an emerging water treatment technology., J. Hazard. Mater. 211-212 (2012) 112-25. doi:10.1016/j.jhazmat.2011.11.073.

[7] U.S. EPA, Drinking Water Contaminant Candidate List 4-Final, United States of America, n.d. https://www.regulations.gov/document?D=EPA-HQ-OW-2012-0217-0071.

[8] J. Dong, C. Wen, D. Liu, W. Zhang, J. Li, H. Jiang, C. Qin, M. Hong, Study on degradation of nitrobenzene in groundwater using emulsified nano-zero-valent iron, J. Nanoparticle Res. 17 (2015) 31. doi:10.1007/s11051-014-2829-9.

[9] X. Ling, J. Li, W. Zhu, Y. Zhu, X. Sun, J. Shen, W. Han, L. Wang, Synthesis of nanoscale zero-valent iron/ordered mesoporous carbon for adsorption and synergistic reduction of nitrobenzene, Chemosphere. 87 (2012) 655-660. doi:10.1016/j.chemosphere.2012.02.002.

[10] J. Dong, Y. Zhao, R. Zhao, R. Zhou, Effects of $\mathrm{pH}$ and particle size on kinetics of nitrobenzene reduction by zero-valent iron, J. Environ. Sci. 22 (2010) 1741-1747. doi:https://doi.org/10.1016/S10010742(09)60314-4.

[11] J.F. Power, J.S. Schepers, Effects of Agriculture on GroundwaterNitrate contamination of groundwater in North America, Agric. Ecosyst. Environ. 26 (1989) 165-187. doi:10.1016/0167-8809(89)90012-1.

[12] S.-S. Chen, H.-D. Hsu, C.-W. Li, A new method to produce nanoscale iron for nitrate removal, J. Nanoparticle Res. 6 (2004) 639-647. doi:10.1007/s11051-004-6672-2. 
[13] Y. Hwang, D.-G. Kim, H.-S. Shin, Mechanism study of nitrate reduction by nano zero valent iron, J. Hazard. Mater. 185 (2011) 1513-1521. doi:http://dx.doi.org/10.1016/j.jhazmat.2010.10.078.

[14] M.A. Liendo, G.E. Navarro, C.H. Sampaio, Nano and Micro ZVI in Aqueous Media: Copper Uptake and Solution Behavior, Water, Air, Soil Pollut. 224 (2013) 1-8. doi:10.1007/s11270-013-1541-1.

[15] W. Zhang, Nanoscale Iron Particles for Environmental Remediation: An Overview, J. Nanoparticle Res. 5 (2003) 323-332. doi:10.1023/A:1025520116015.

[16] X. Lv, Y. Hu, J. Tang, T. Sheng, G. Jiang, X. Xu, Effects of co-existing ions and natural organic matter on removal of chromium (VI) from aqueous solution by nanoscale zero valent iron (nZVI)-Fe3O4 nanocomposites, Chem. Eng. J. 218 (2013) 55-64. doi:https://doi.org/10.1016/j.cej.2012.12.026.

[17] F. Fu, D.D. Dionysiou, H. Liu, The use of zero-valent iron for groundwater remediation and wastewater treatment: A review, J. Hazard. Mater. 267 (2014) 194-205. doi:10.1016/j.jhazmat.2013.12.062.

[18] G. Tchobanoglous, F.L. Burton, H.D. Stensel, Wastewater Engineering: Treatment and Reuse - Metcalf \& Eddy, 4th ed., McGraw-Hill, New York, NY, USA, 2003.

[19] A. Bhatnagar, W. Hogland, M. Marques, M. Sillanpää, An overview of the modification methods of activated carbon for its water treatment applications, Chem. Eng. J. 219 (2013) 499-511. doi:10.1016/j.cej.2012.12.038.

[20] H. Sontheimer, J.C. Crittenden, R.S. Summers, C. Hubele, Activated carbon for water treatment, 2nd ed., DVGW-Forschungsstelle, Engler-Bunte-Institut, Universitat Karlsruhe (TH), Hannover, Germany, 1988.

[21] K.Y. Foo, B.H. Hameed, Detoxification of pesticide waste via activated carbon adsorption process, J. Hazard. Mater. 175 (2010) 1-11. doi:10.1016/j.jhazmat.2009.10.014.

[22] Z. Yu, S. Peldszus, P.M. Huck, Adsorption of Selected Pharmaceuticals and an Endocrine Disrupting Compound by Granular Activated Carbon. 1. Adsorption Capacity and Kinetics, Environ. Sci. Technol. 
43 (2009) 1467-1473. doi:10.1021/es801961y.

[23] M.O. Corapcioglu, C.P. Huang, The adsorption of heavy metals onto hydrous activated carbon, Water Res. 21 (1987) 1031-1044. doi:10.1016/0043-1354(87)90024-8.

[24] A. Bhatnagar, M. Sillanpää, A review of emerging adsorbents for nitrate removal from water, Chem. Eng. J. 168 (2011) 493-504. doi:10.1016/j.cej.2011.01.103.

[25] L.B. Hoch, E.J. Mack, B.W. Hydutsky, J.M. Hershman, J.M. Skluzacek, T.E. Mallouk, Carbothermal Synthesis of Carbon-supported Nanoscale Zero-valent Iron Particles for the Remediation of Hexavalent Chromium, Environ. Sci. Technol. 42 (2008) 2600-2605. doi:10.1021/es702589u.

[26] K. Mackenzie, S. Bleyl, A. Georgi, F.-D. Kopinke, Carbo-Iron - An Fe/AC composite - As alternative to nano-iron for groundwater treatment, Water Res. 46 (2012) 3817-3826. doi:http://dx.doi.org/10.1016/j.watres.2012.04.013.

[27] J. Zhan, I. Kolesnichenko, B. Sunkara, J. He, G.L. McPherson, G. Piringer, V.T. John, Multifunctional iron-carbon nanocomposites through an aerosol-based process for the in situ remediation of chlorinated hydrocarbons., Environ. Sci. Technol. 45 (2011) 1949-1954. doi:10.1021/es103493e.

[28] P.D. Mines, J. Byun, Y. Hwang, H.A. Patel, H.R. Andersen, C.T. Yavuz, Nanoporous networks as effective stabilisation matrices for nanoscale zero-valent iron and groundwater pollutant removal, J. Mater. Chem. A. 4 (2016) 632-639. doi:10.1039/C5TA05025A.

[29] H.A. Patel, C.T. Yavuz, Highly optimized CO2 capture by inexpensive nanoporous covalent organic polymers and their amine composites, Faraday Discuss. 183 (2015) 401-412. doi:10.1039/C5FD00099H.

[30] H.A. Patel, F. Karadas, A. Canlier, J. Park, E. Deniz, Y. Jung, M. Atilhan, C.T. Yavuz, High capacity carbon dioxide adsorption by inexpensive covalent organic polymers, J. Mater. Chem. 22 (2012) 84318437. doi:10.1039/c2jm30761h. 
[31] D. Ko, H.A. Patel, C.T. Yavuz, Synthesis of nanoporous 1,2,4-oxadiazole networks with high CO2 capture capacity, Chem. Commun. 51 (2015) 2915-2917. doi:10.1039/C4CC08649J.

[32] H.A. Patel, M.S. Yavuz, C.T. Yavuz, Exceptional organic solvent uptake by disulfide-linked polymeric networks, RSC Adv. 4 (2014) 24320-24323. doi:10.1039/c4ra03355h.

[33] P.D. Mines, D. Thirion, B. Uthuppu, Y. Hwang, M.H. Jakobsen, H.R. Andersen, C.T. Yavuz, Covalent organic polymer functionalization of activated carbon surfaces through acyl chloride for environmental clean-up, Chem. Eng. J. 309 (2017) 766-771. doi:http://dx.doi.org/10.1016/j.cej.2016.10.085.

[34] T. Phenrat, N. Saleh, K. Sirk, R.D. Tilton, G. V. Lowry, Aggregation and Sedimentation of Aqueous Nanoscale Zerovalent Iron Dispersions, Environ. Sci. Technol. 41 (2006) 284-290. doi:10.1021/es061349a.

[35] F. He, D. Zhao, Preparation and Characterization of a New Class of Starch-Stabilized Bimetallic Nanoparticles for Degradation of Chlorinated Hydrocarbons in Water, Environ. Sci. Technol. 39 (2005) 3314-3320. doi:10.1021/es048743y.

[36] Y. Hwang, Y.-C. Lee, P.D. Mines, Y.S. Huh, H.R. Andersen, Nanoscale zero-valent iron (nZVI) synthesis in a Mg-aminoclay solution exhibits increased stability and reactivity for reductive decontamination, Appl. Catal. B Environ. 147 (2014) 748-755. doi:10.1016/j.apcatb.2013.10.017.

[37] M.G. Schwab, B. Fassbender, H.W. Spiess, A. Thomas, X. Feng, K. Müllen, Catalyst-free preparation of melamine-based microporous polymer networks through Schiff base chemistry., J. Am. Chem. Soc. 131 (2009) 7216-7217. doi:10.1021/ja902116f.

[38] Y. Hwang, A. Salatas, P.D. Mines, M.H. Jakobsen, H.R. Andersen, Graduated characterization method using a multi-well microplate for reducing reactivity of nanoscale zero valent iron materials, Appl. Catal. B Environ. 181 (2016) 314-320. doi:10.1016/j.apcatb.2015.07.041. 
[39] J.N. Fiedor, W.D. Bostick, R.J. Jarabek, J. Farrell, Understanding the Mechanism of Uranium Removal from Groundwater by Zero-Valent Iron Using X-ray Photoelectron Spectroscopy, Environ. Sci. Technol. 32 (1998) 1466-1473. doi:10.1021/es970385u.

[40] J. Xiao, Q. Yue, B. Gao, Y. Sun, J. Kong, Y. Gao, Q. Li, Y. Wang, Performance of activated carbon/nanoscale zero-valent iron for removal of trihalomethanes (THMs) at infinitesimal concentration in drinking water, Chem. Eng. J. 253 (2014) 63-72. doi:10.1016/j.cej.2014.05.030.

[41] H.-H. Tseng, J.-G. Su, C. Liang, Synthesis of granular activated carbon/zero valent iron composites for simultaneous adsorption/dechlorination of trichloroethylene., J. Hazard. Mater. 192 (2011) 500-506. doi:10.1016/j.jhazmat.2011.05.047.

[42] Y. Liu, S.A. Majetich, R.D. Tilton, D.S. Sholl, G. V. Lowry, TCE Dechlorination Rates, Pathways, and Efficiency of Nanoscale Iron Particles with Different Properties, Environ. Sci. Technol. 39 (2005) 13381345. doi:10.1021/es049195r.

[43] Y. Su, A.S. Adeleye, Y. Huang, X. Zhou, A.A. Keller, Y. Zhang, Direct Synthesis of Novel and Reactive Sulfide-modified Nano Iron through Nanoparticle Seeding for Improved Cadmium-Contaminated Water Treatment, Sci. Rep. 6 (2016) 24358. doi:10.1038/srep24358.

[44] S. Grimme, Do Special Noncovalent $\pi-\pi$ Stacking Interactions Really Exist?, Angew. Chemie Int. Ed. 47 (2008) 3430-3434. doi:10.1002/anie.200705157.

[45] B. Lippa, G. Pan, M. Corbett, C. Li, G.S. Kauffman, J. Pandit, S. Robinson, L. Wei, E. Kozina, E.S. Marr, G. Borzillo, E. Knauth, E.G. Barbacci-Tobin, P. Vincent, M. Troutman, D. Baker, F. Rajamohan, S. Kakar, T. Clark, J. Morris, Synthesis and structure based optimization of novel Akt inhibitors, Bioorg. Med. Chem. Lett. 18 (2008) 3359-3363. doi:10.1016/j.bmcl.2008.04.034.

[46] Y. Morisaki, Y. Chujo, Synthesis of \&pi;-Stacked Polymers on the Basis of [2.2]Paracyclophane, Bull. Chem. Soc. Jpn. 82 (2009) 1070-1082. doi:10.1246/bcsj.82.1070. 
[47] F.D. Lewis, P. Daublain, G.B. Delos Santos, W. Liu, A.M. Asatryan, S.A. Markarian, T. Fiebig, M. Raytchev, Q. Wang, Dynamics and Mechanism of Bridge-Dependent Charge Separation in Pyrenylurea-Nitrobenzene $\pi$-Stacked Protophanes, J. Am. Chem. Soc. 128 (2006) 4792-4801. doi:10.1021/ja058050x.

[48] H.J. Jung, N. Singh, D.O. Jang, Highly Fe3+ selective ratiometric fluorescent probe based on iminelinked benzimidazole, Tetrahedron Lett. 49 (2008) 2960-2964. doi:https://doi.org/10.1016/j.tetlet.2008.03.002.

[49] C. Lodeiro, R. Bastida, A. de Blas, D.E. Fenton, A. Macías, A. Rodríguez, T. Rodríguez-Blas, Complexes of lead(II) and lanthanide(III) ions with two novel 26-membered-imine and -amine macrocycles derived from 2,6-bis(2-formylphenoxymethyl)pyridine, Inorganica Chim. Acta. 267 (1998) 55-62. doi:https://doi.org/10.1016/S0020-1693(97)05552-7. 
Table 1 Surface atomic percentages of the different GAC materials, as determined by XPS.

\begin{tabular}{|l|c|c|c|}
\hline Element & GAC & GAC-COP & GAC-COP-Fe \\
\hline $\mathrm{C}$ & 92.0 & 61.0 & 48.5 \\
\hline $\mathrm{O}$ & 8.0 & 6.4 & 22.4 \\
\hline $\mathrm{N}$ & - & 32.6 & 19.7 \\
\hline $\mathrm{Fe}$ & - & - & 2.2 \\
\hline $\mathrm{Na}$ & - & - & 7.2 \\
\hline
\end{tabular}




\section{Granular activated carbon with grafted nanoporous polymer enhances nanoscale zero-valent iron impregnation and water contaminant removal}

Paul D. Mines ${ }^{\mathrm{a}}$, Basil Uthuppu ${ }^{\mathrm{b}}$, Damien Thirion ${ }^{\mathrm{c}}$, Mogens H. Jakobsen ${ }^{\mathrm{b}}$, Cafer T. Yavuz ${ }^{\mathrm{c}}$, Henrik R. Andersen ${ }^{\mathrm{a}}$, and Yuhoon Hwang d,*

${ }^{a}$ Department of Environmental Engineering, Technical University of Denmark, Miljøvej. B113, DK-2800 Kongens Lyngby, Denmark

${ }^{\mathrm{b}}$ Department of Micro- and Nanotechnology, Technical University of Denmark, Ørsteds Plads, B345B, DK2800 Kongens Lyngby, Denmark

${ }^{c}$ Graduate School of EEWS, Korea Advanced Institute of Science and Technology, 291 Daehak-ro, Yuseong-gu, Daejeon 34141, Republic of Korea

d Department of Environmental Engineering, Seoul National University of Science and Technology, 232 Gongneung-ro, Nowon-gu, Seoul 01811, Republic of Korea

\section{Highlights}

- Nanoporous polymeric networks are chemically grafted to activated carbon granules

- Hybrid polymer/carbon composites are impregnated with nanoscale zero-valent iron

- Composite materials increase nZVI content and protect against oxidation

- Materials provide effective simultaneous adsorption and degradation of pollutants 

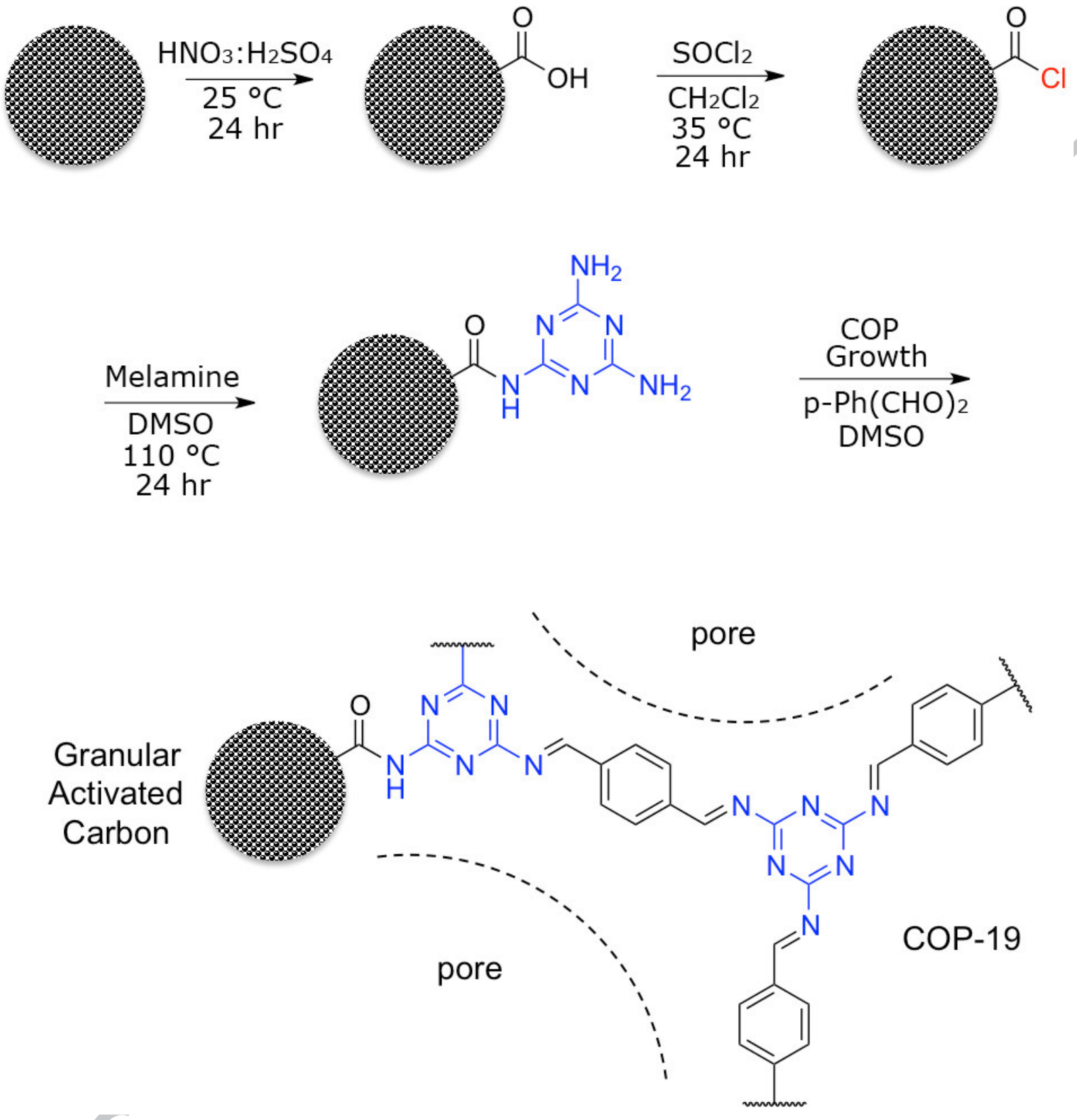


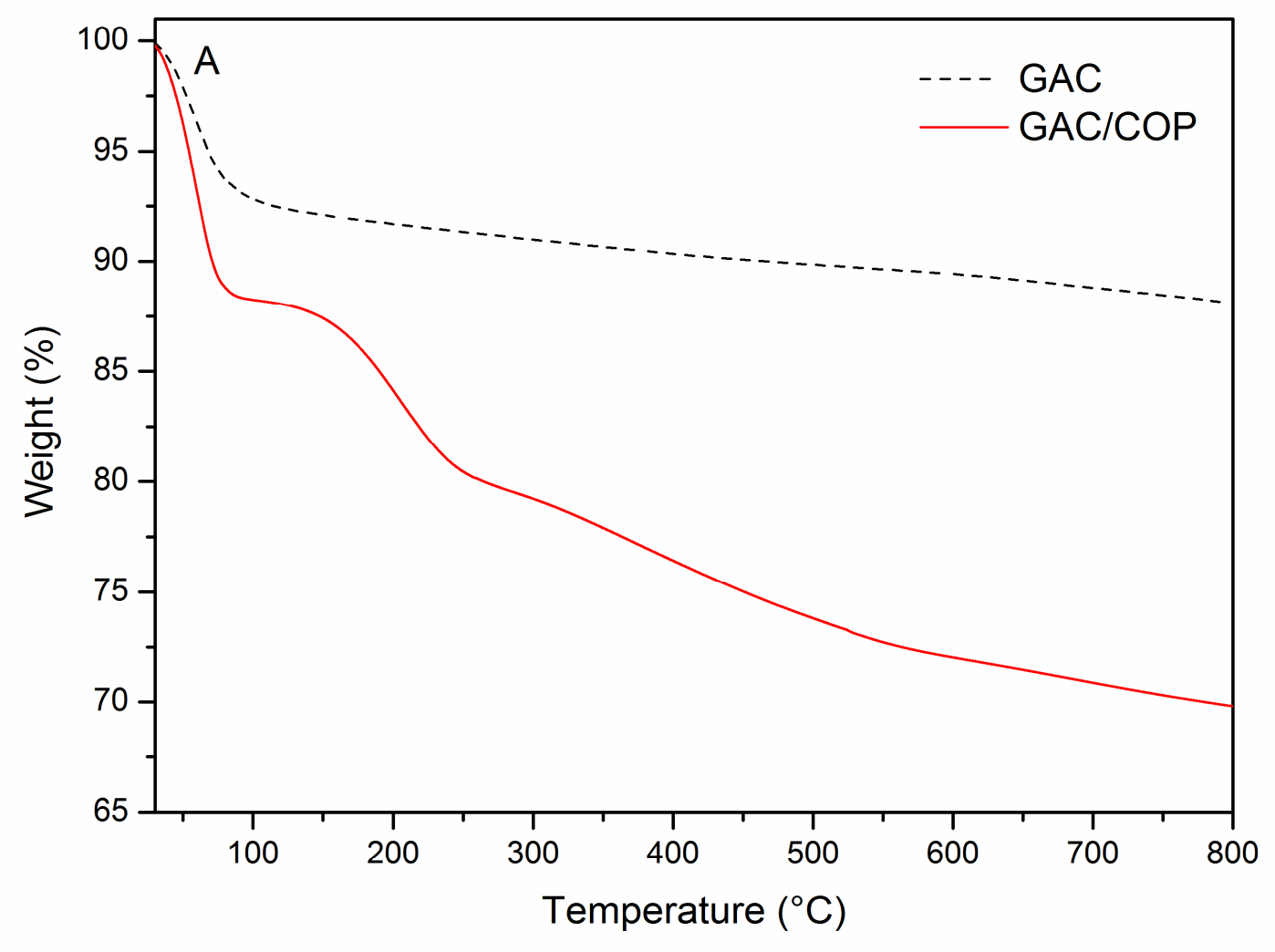




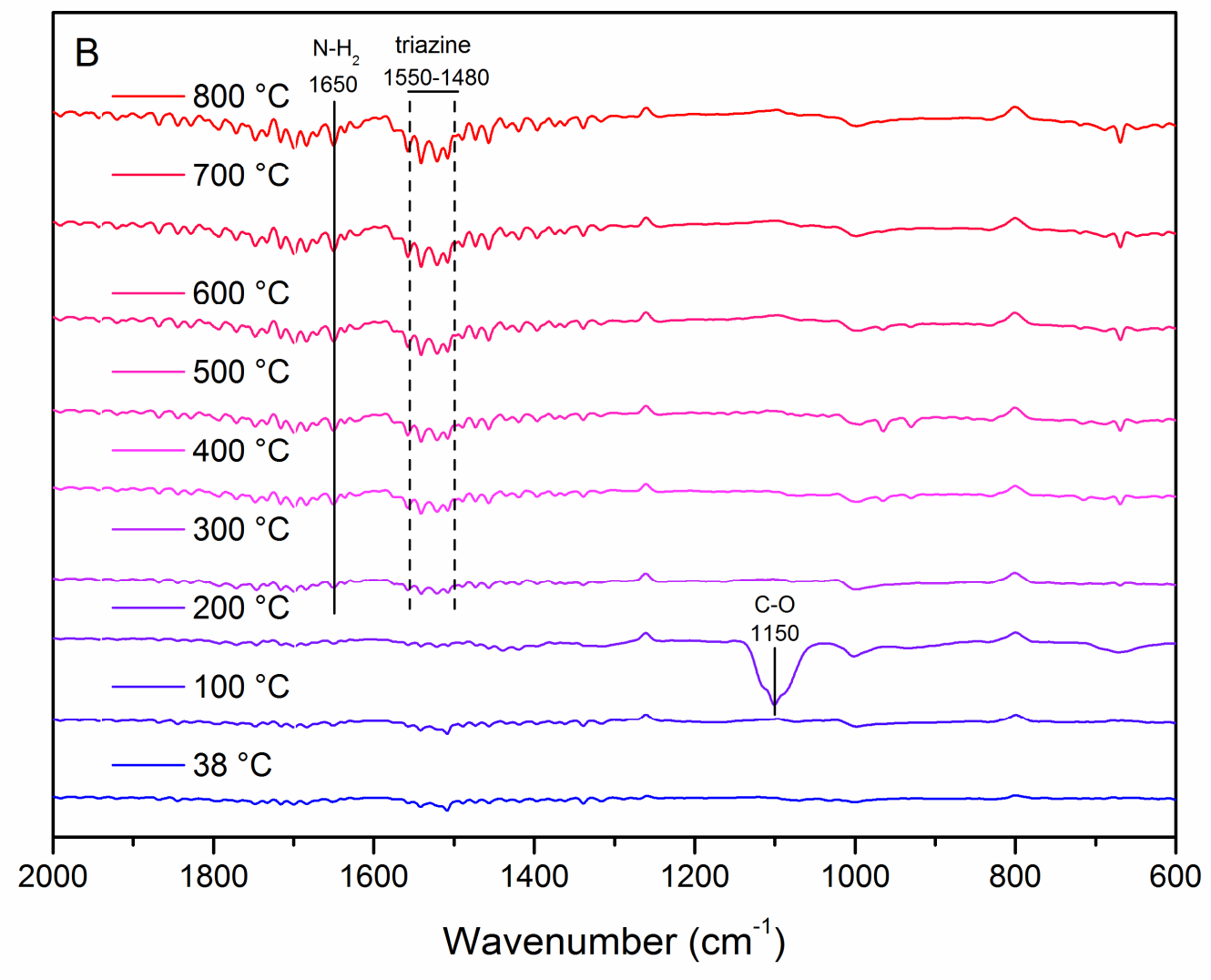




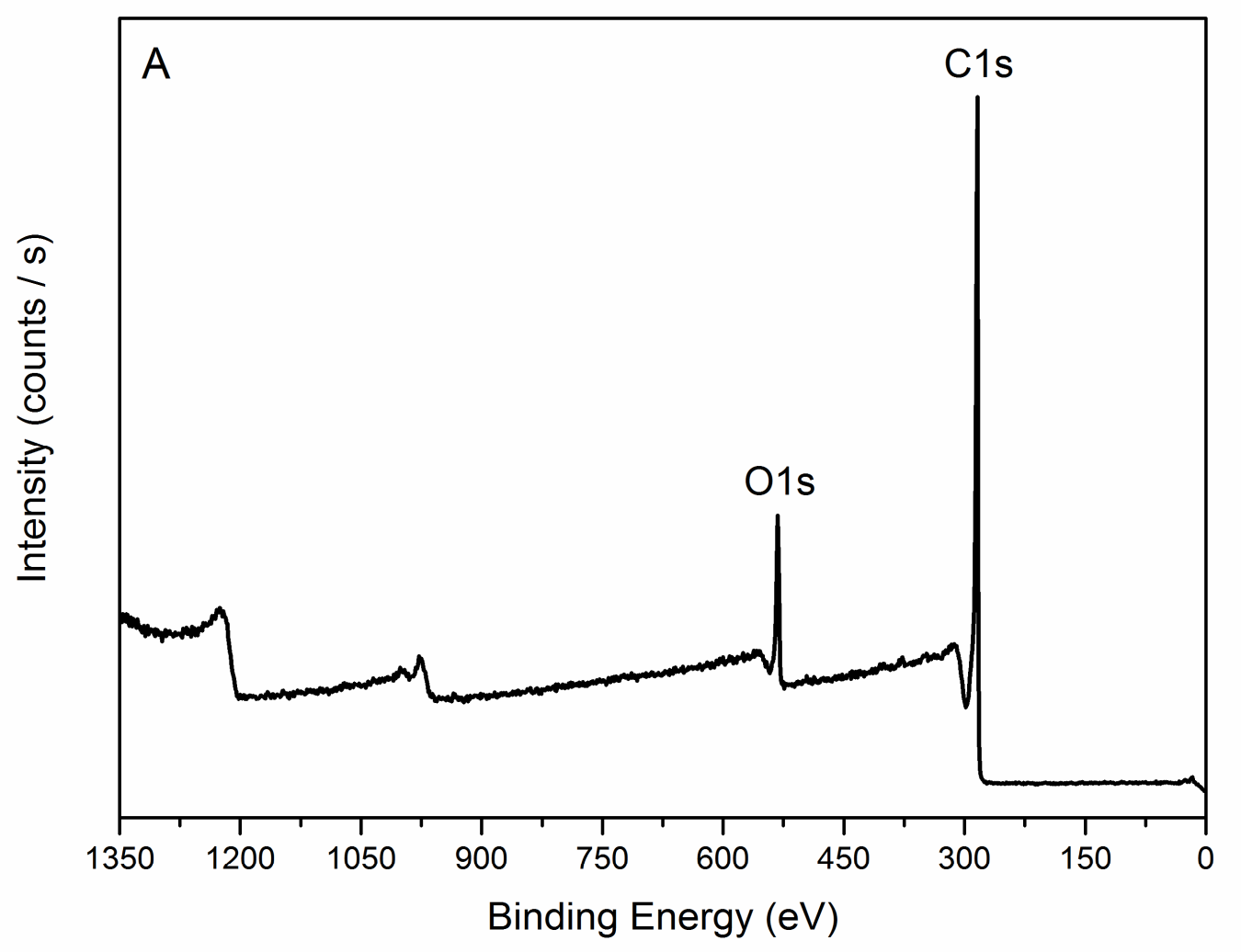




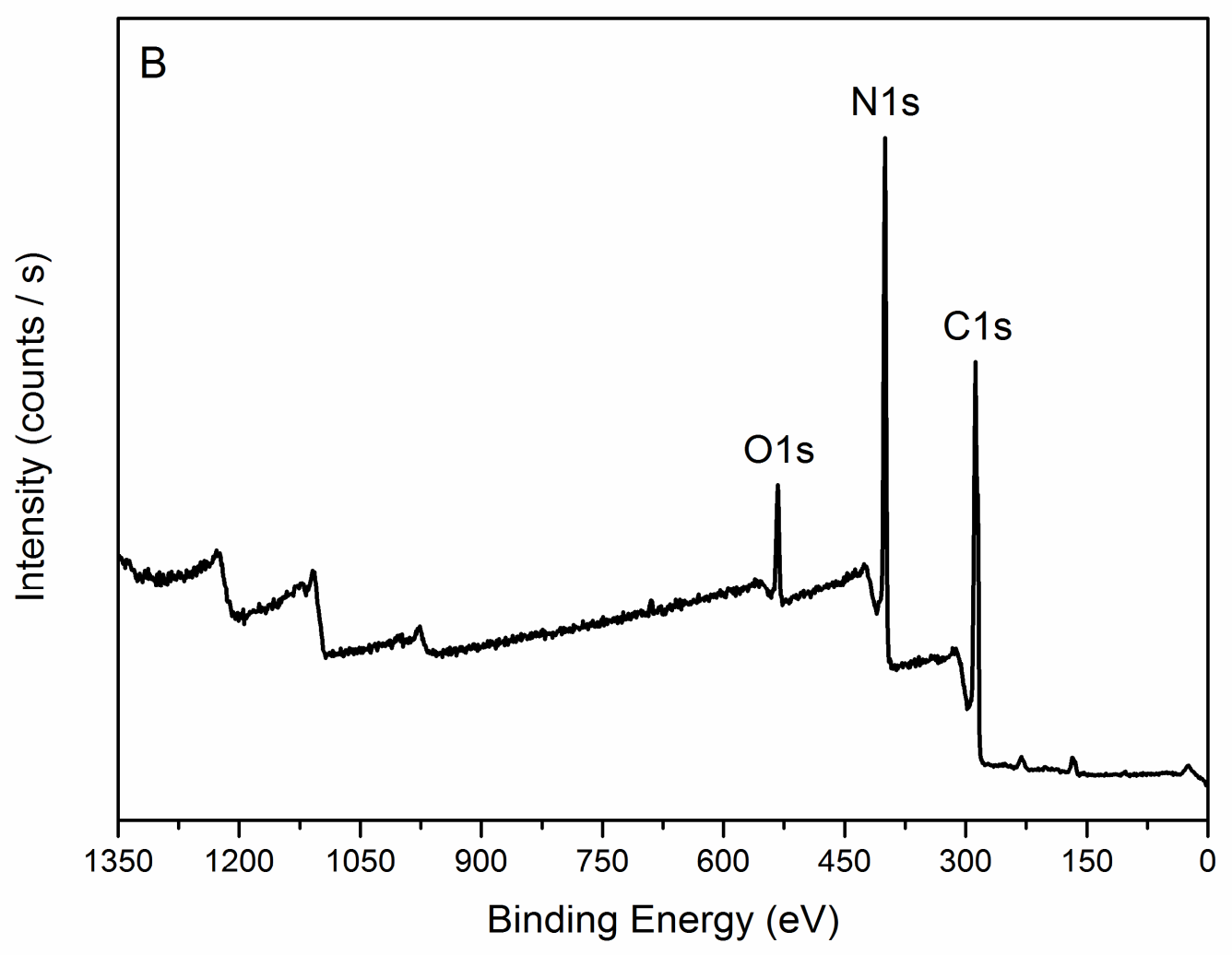




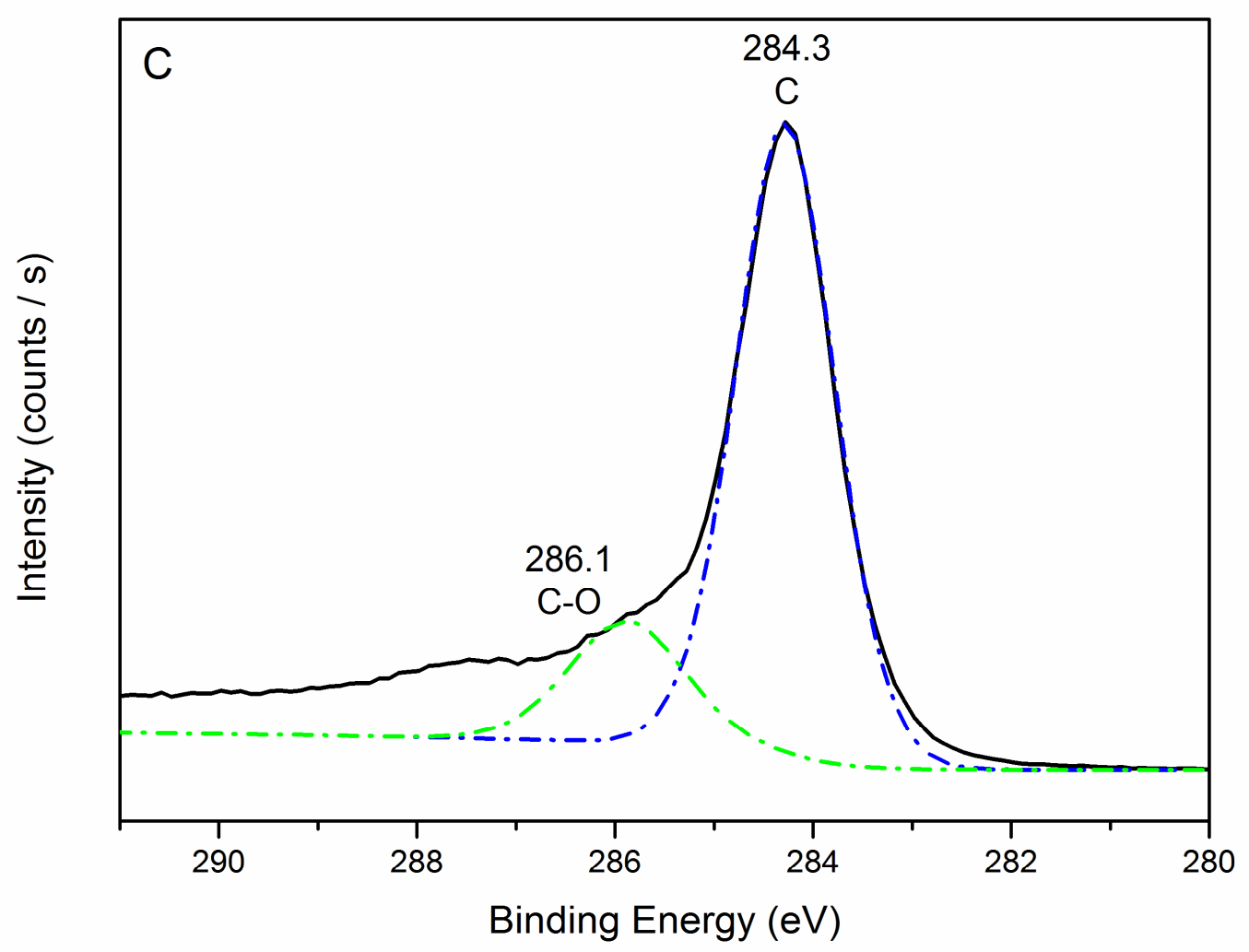




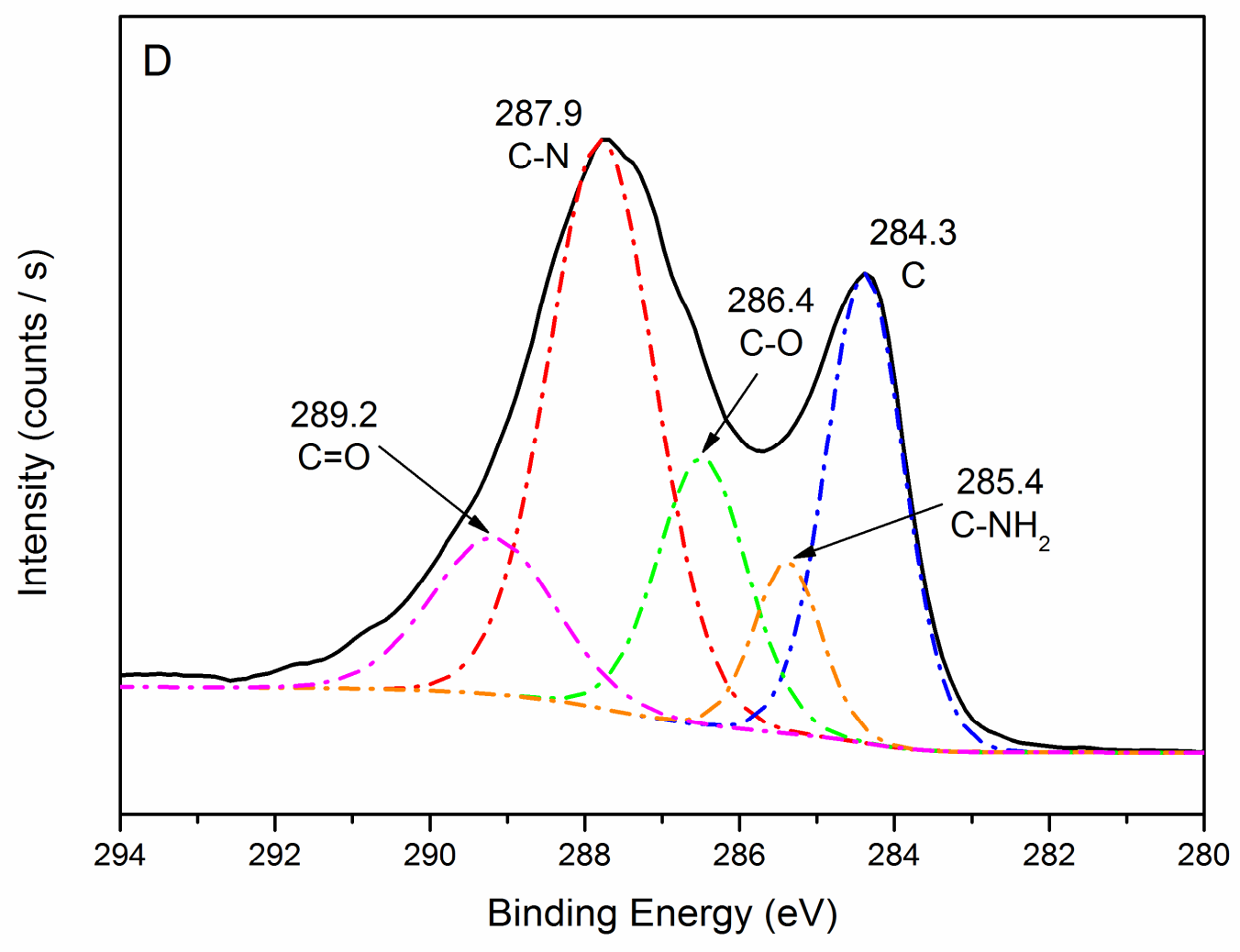




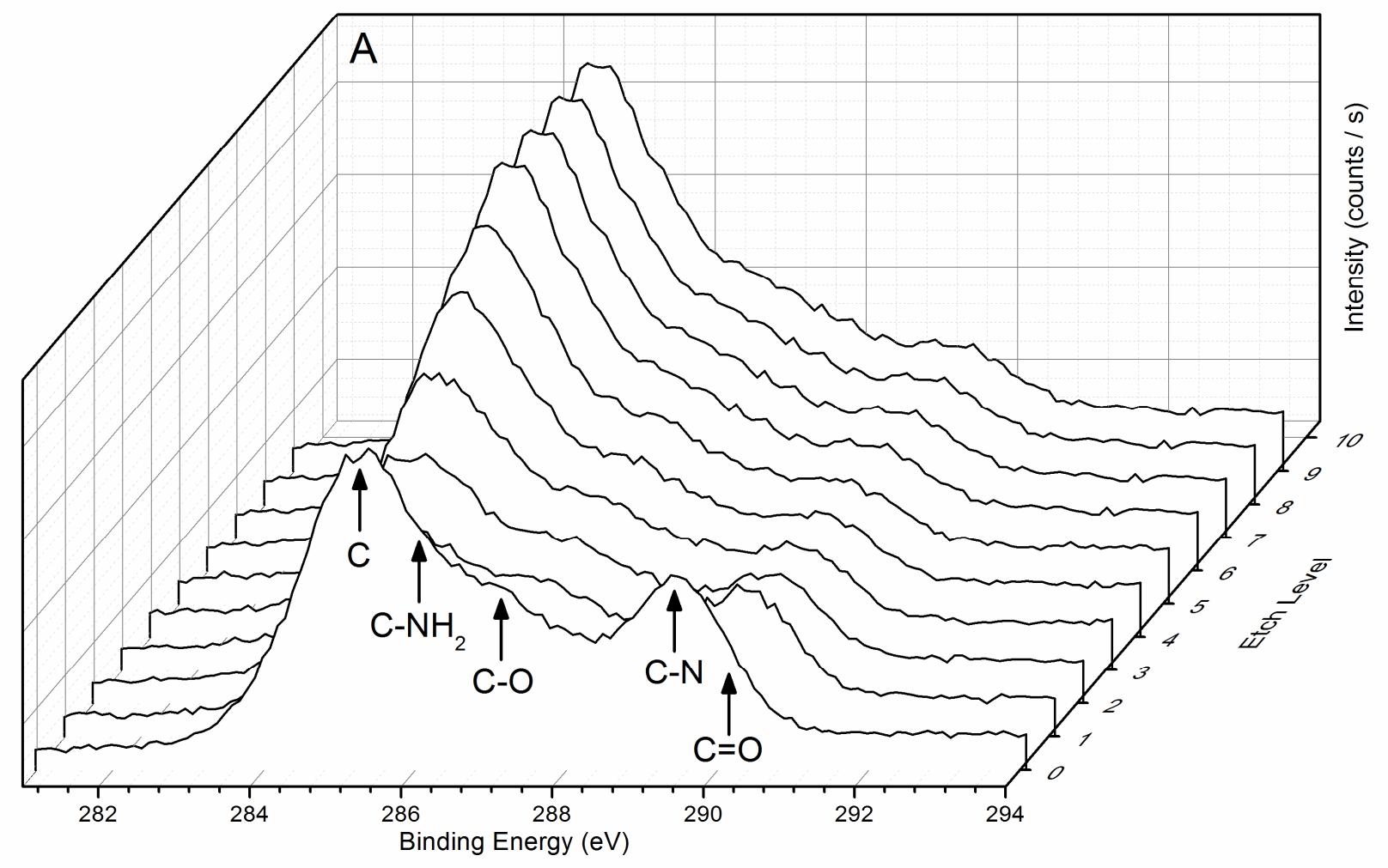




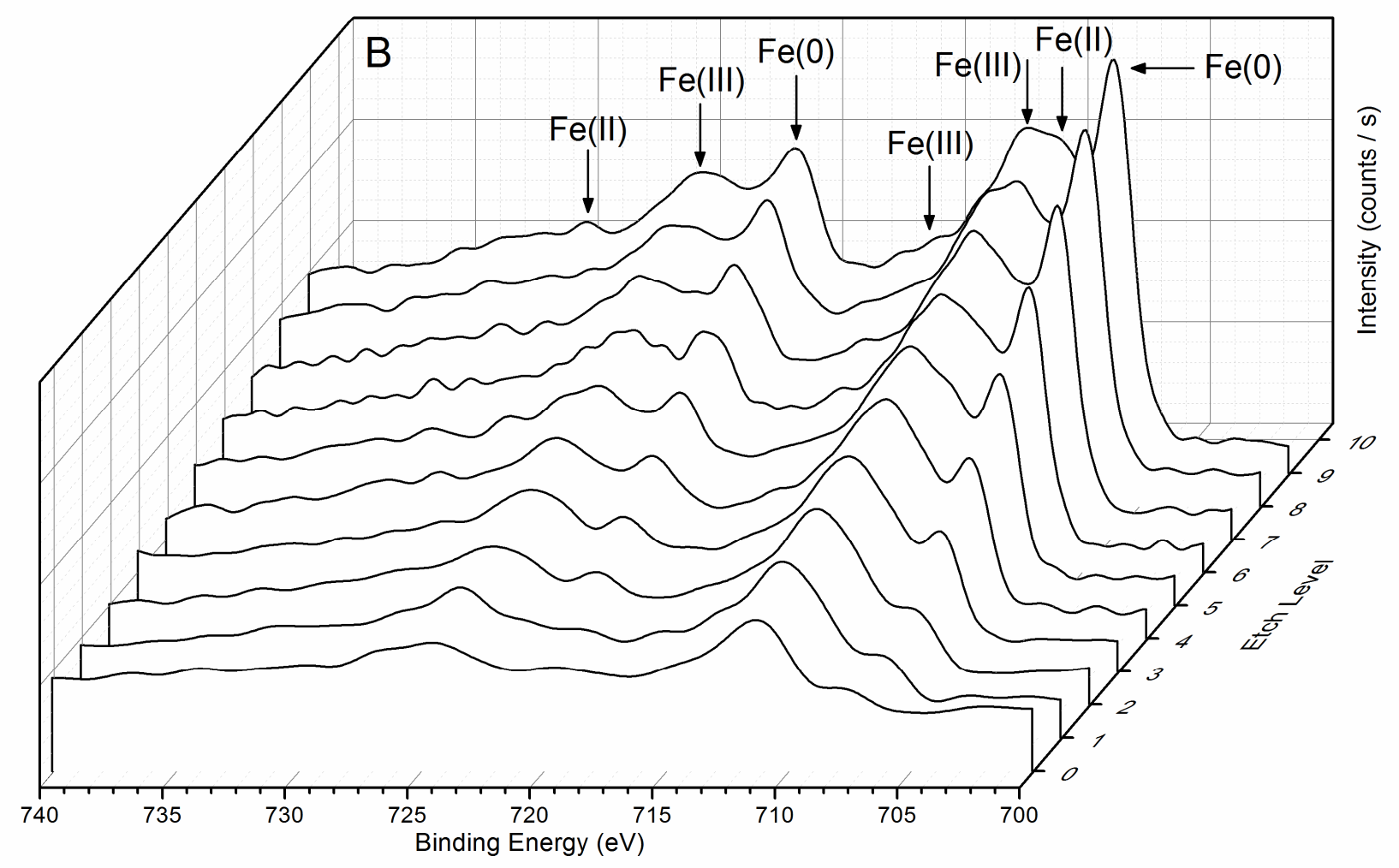




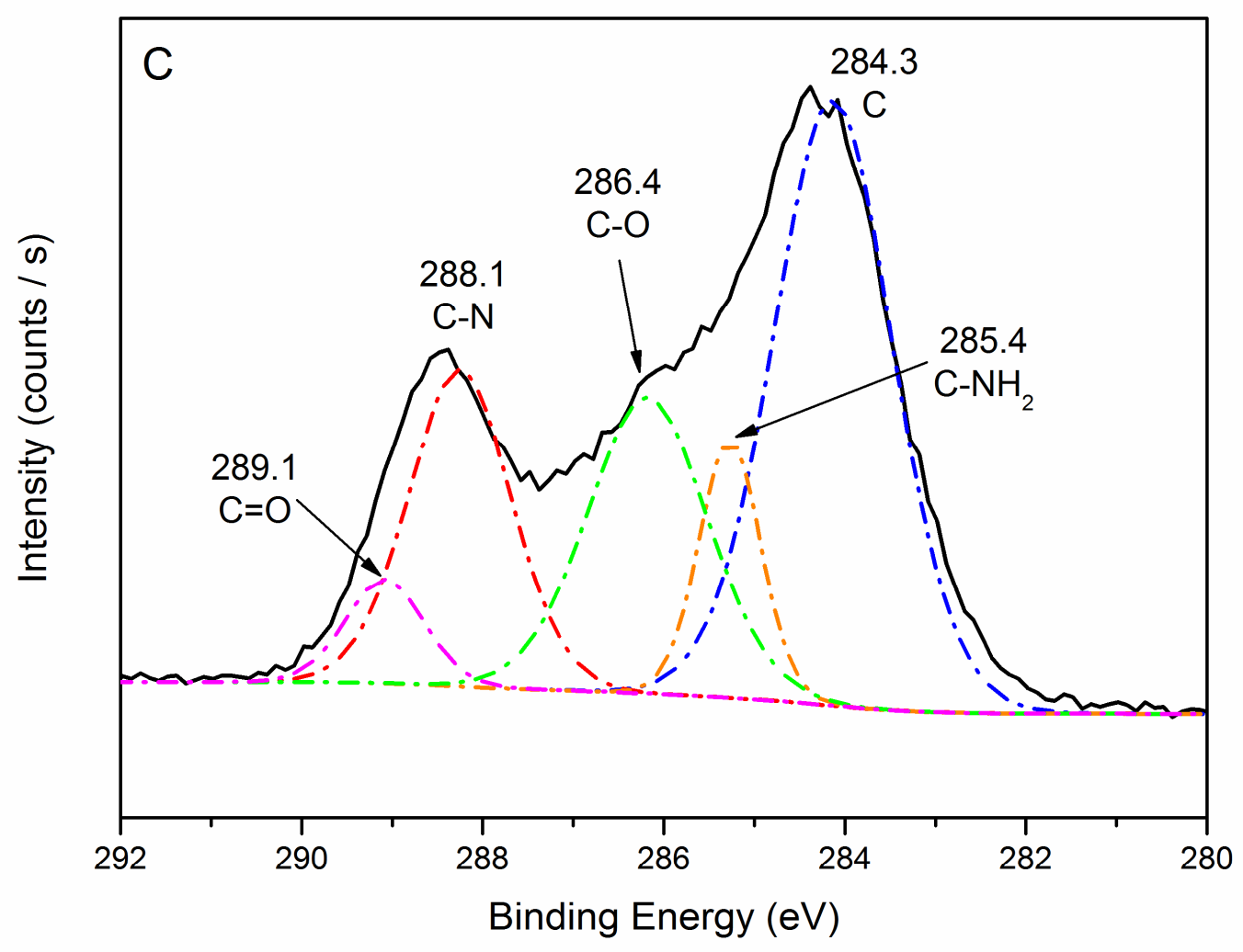




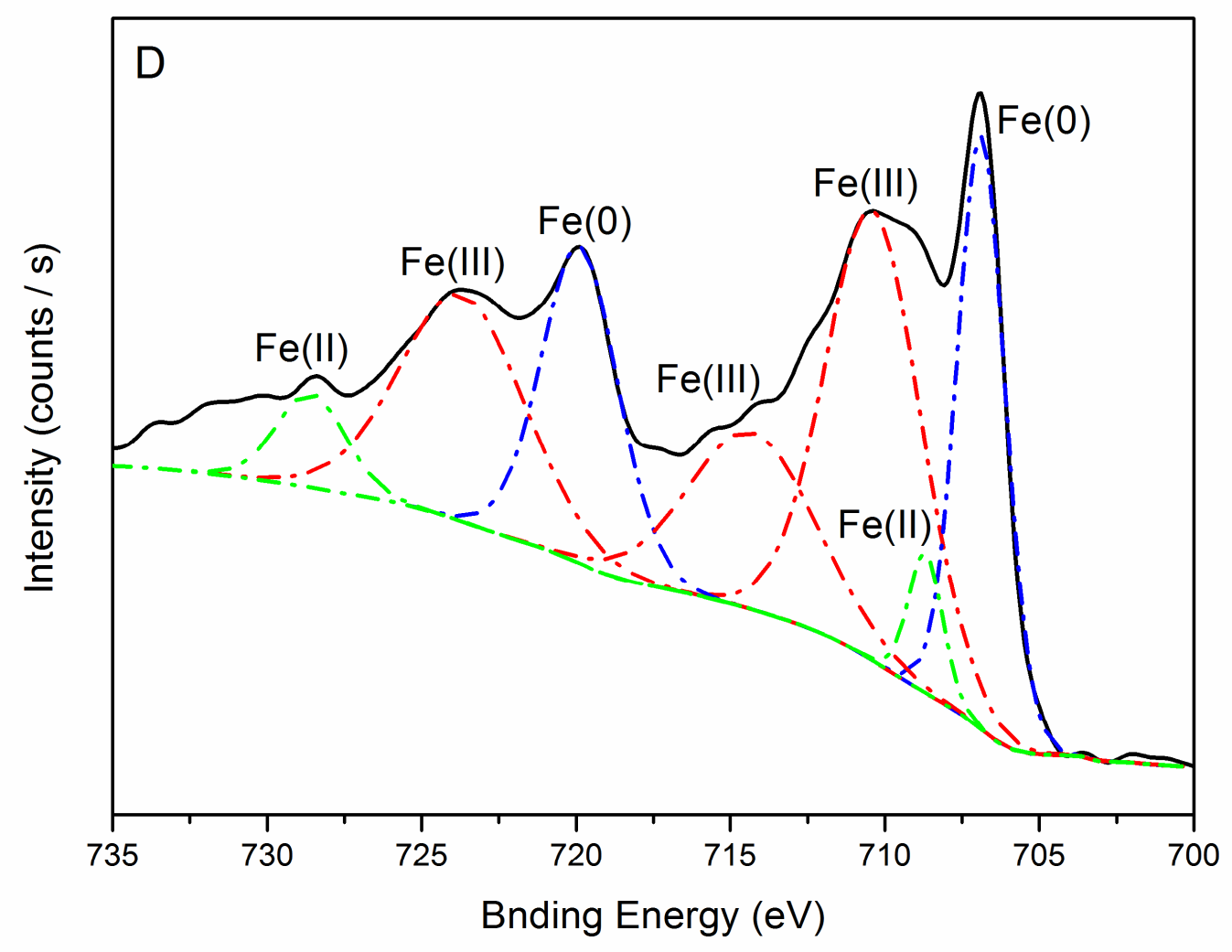



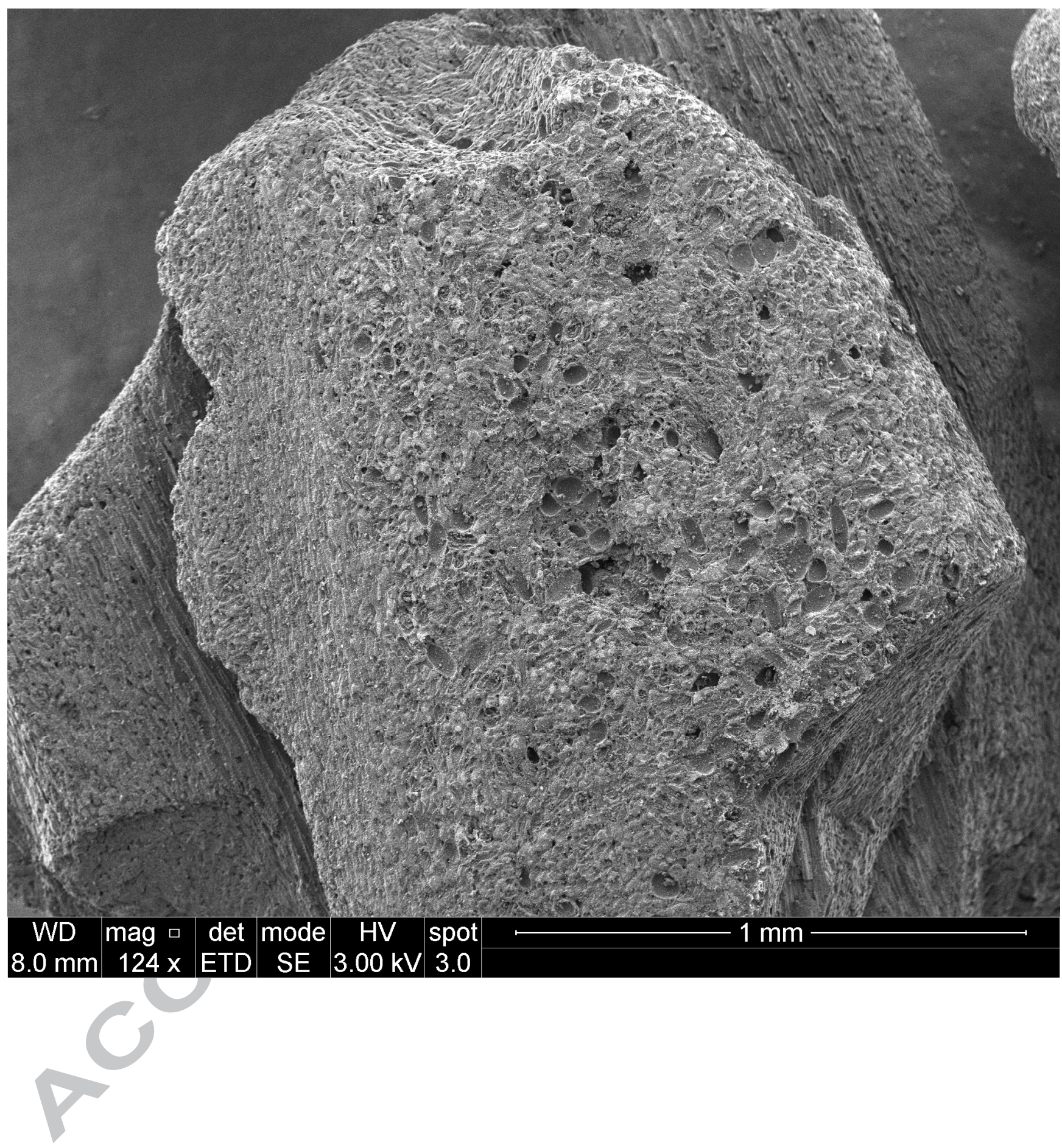

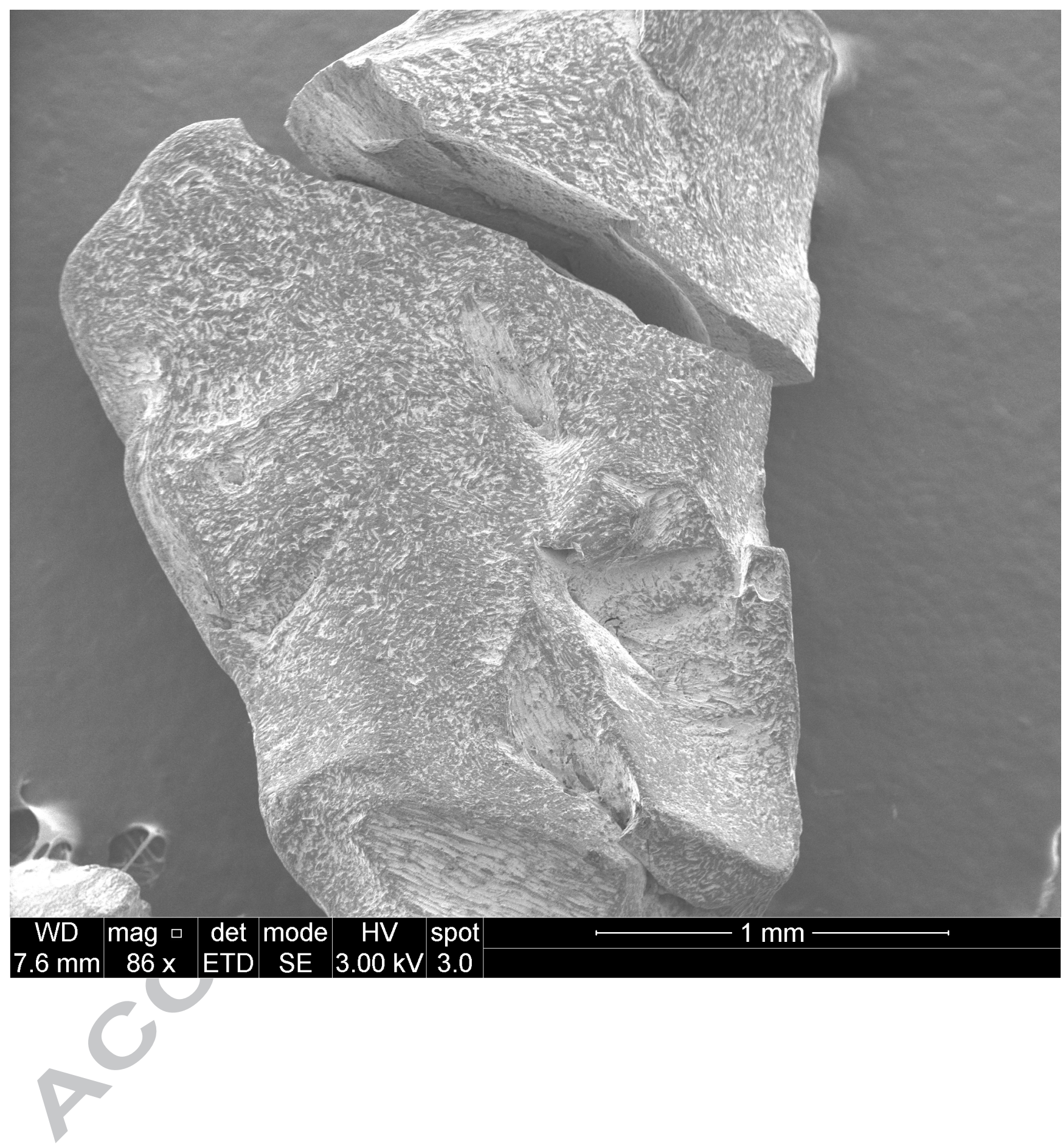


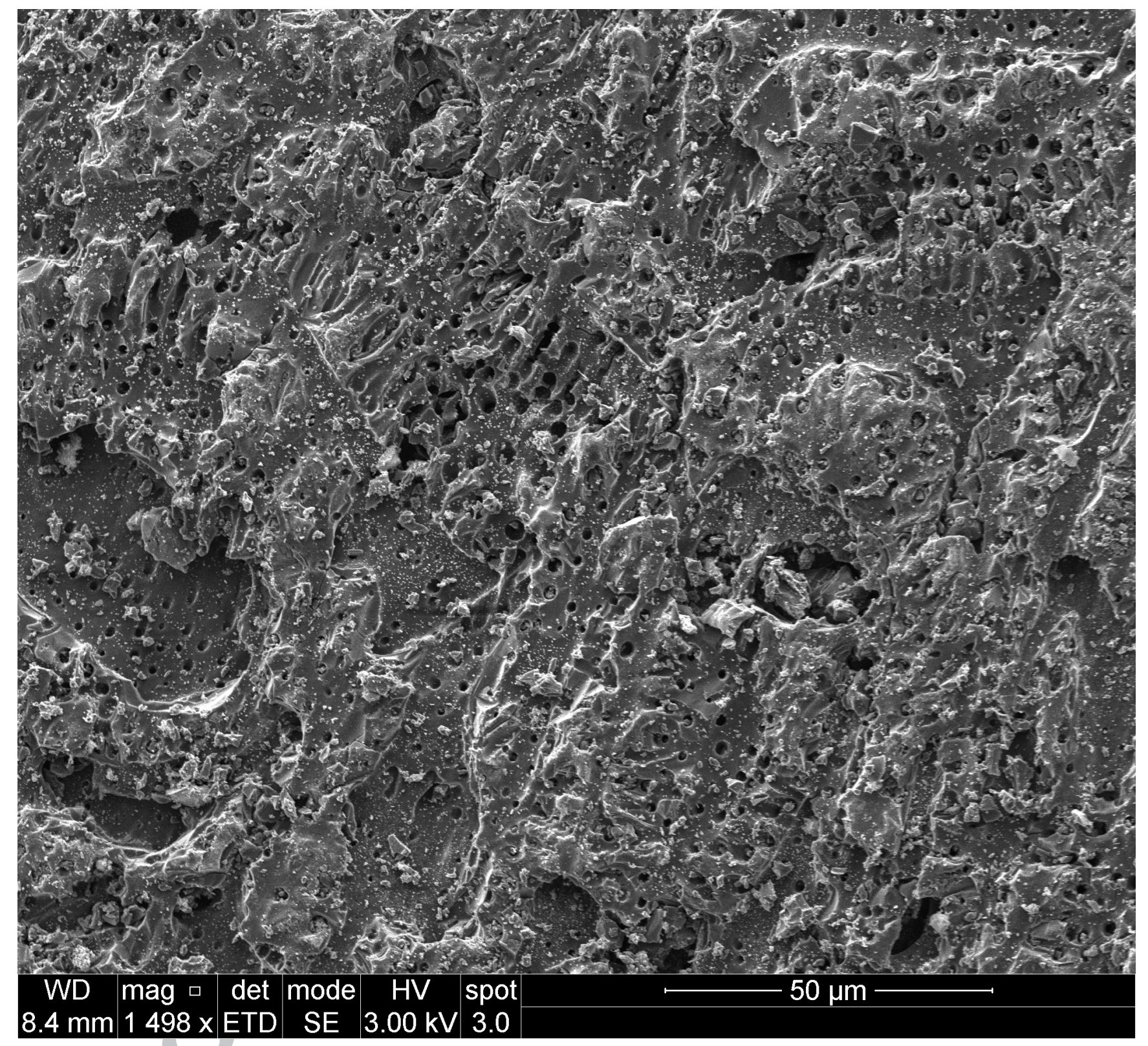




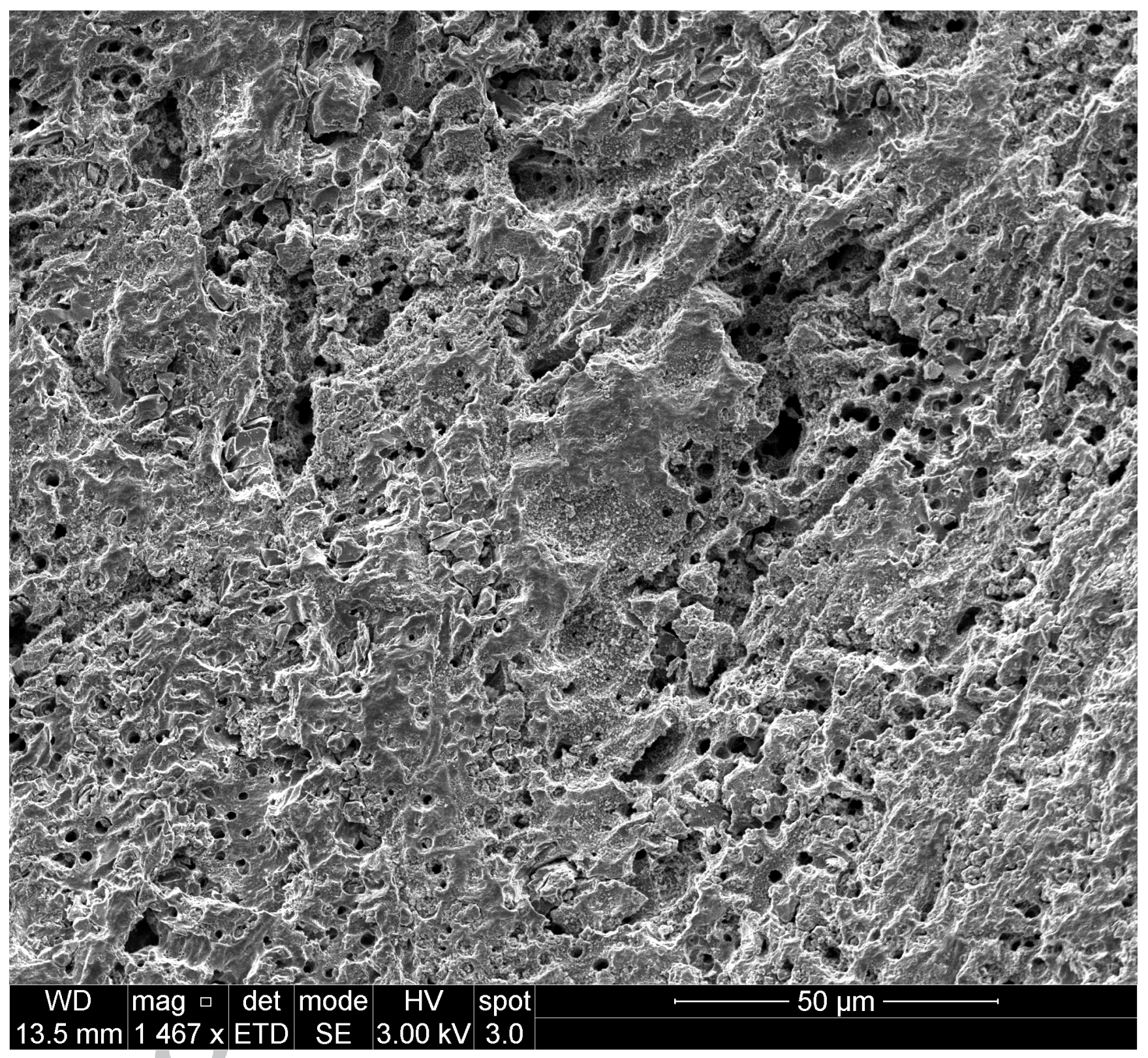



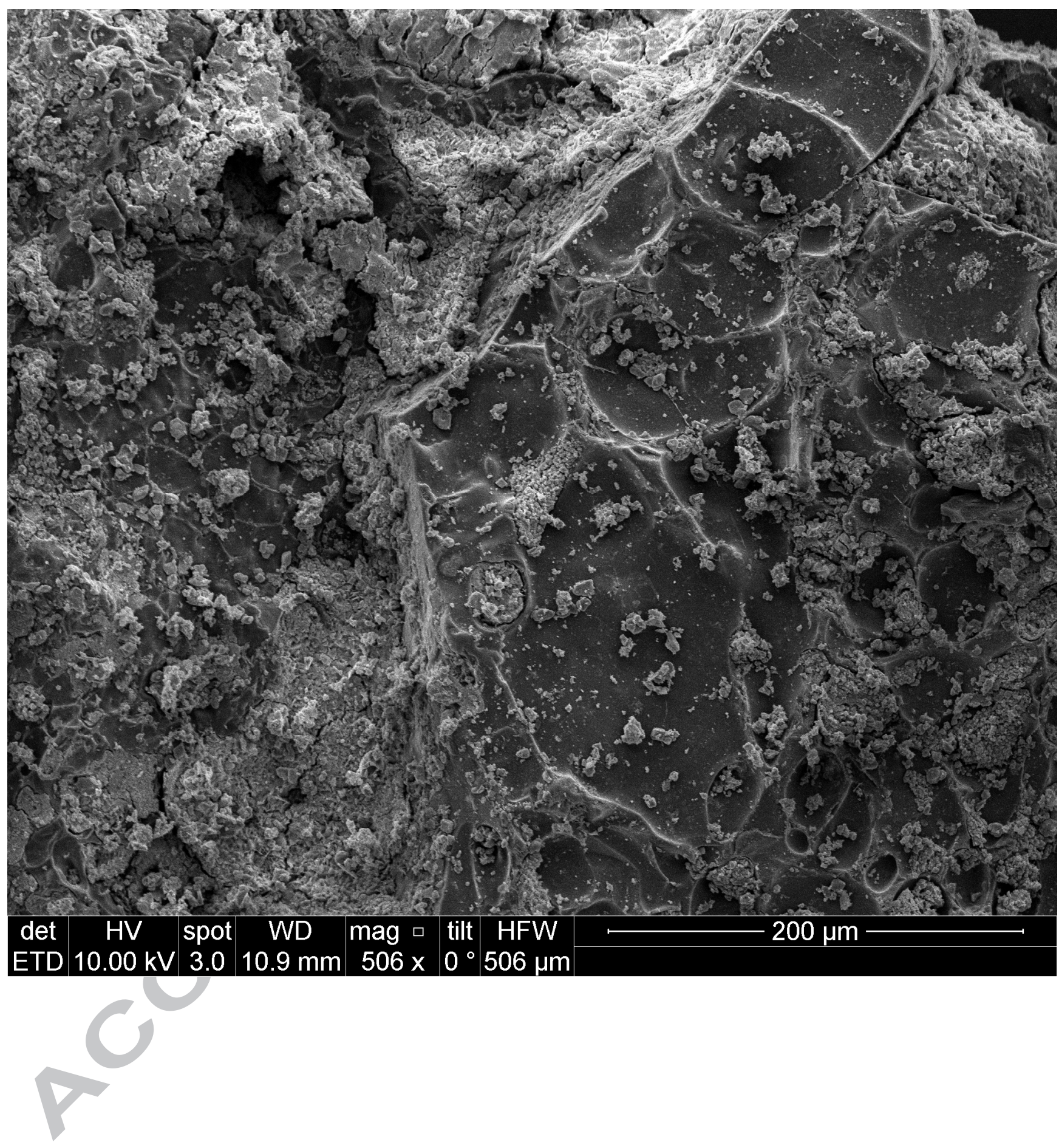

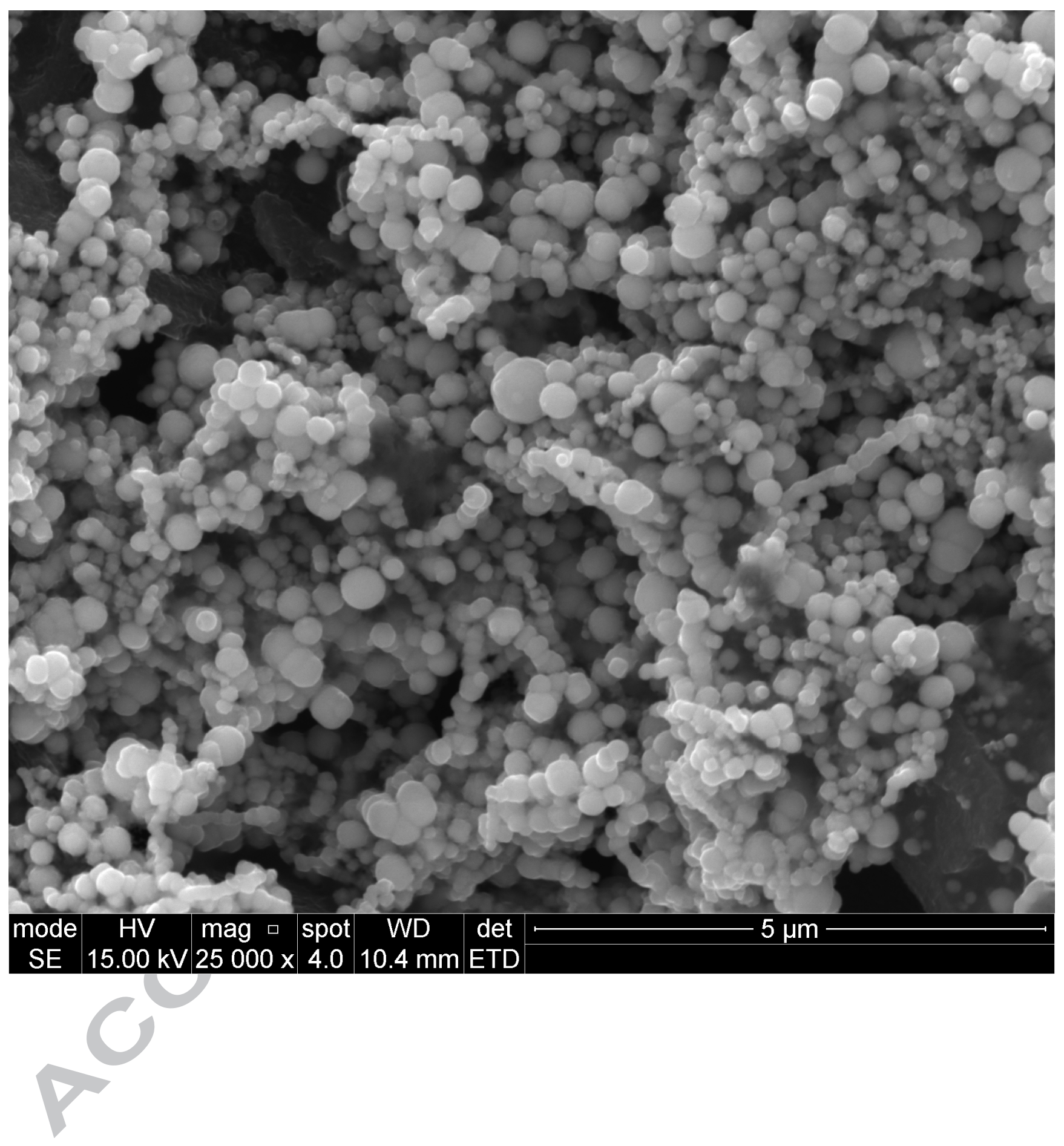


\section{TESH a}

HU.

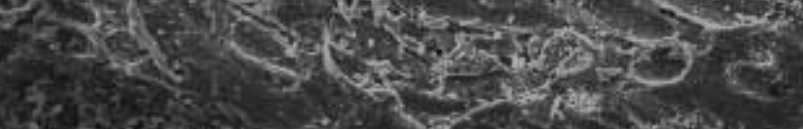
$3,0,1)$

65. 25.6.

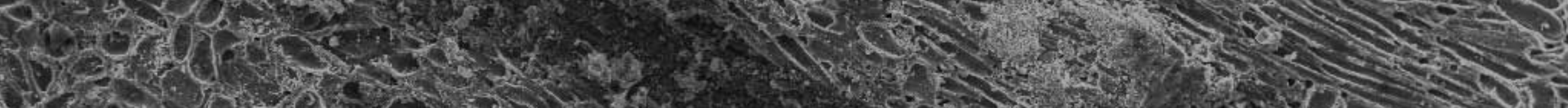

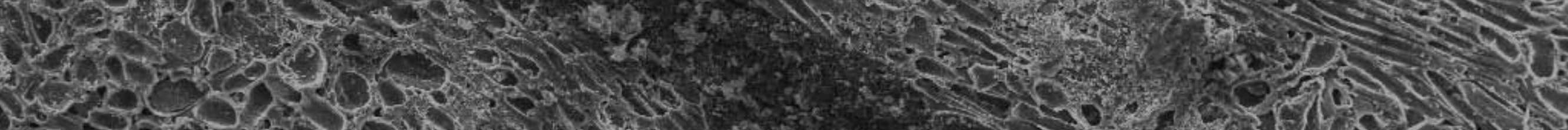
2.

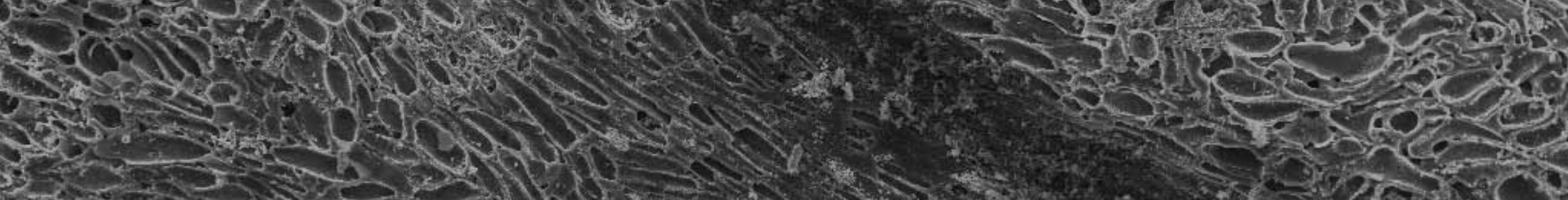

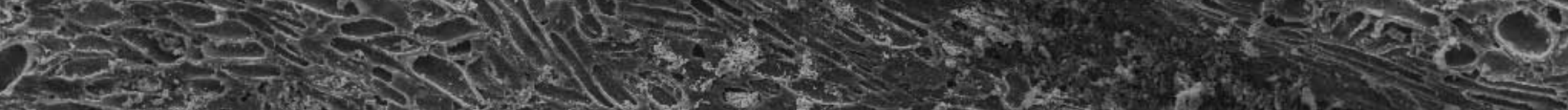

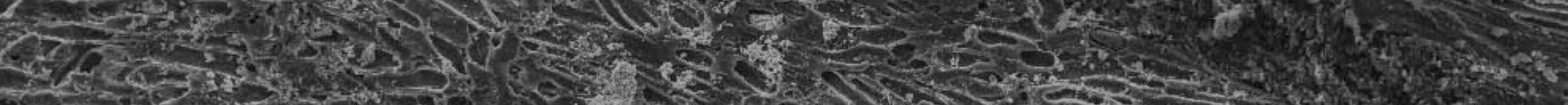

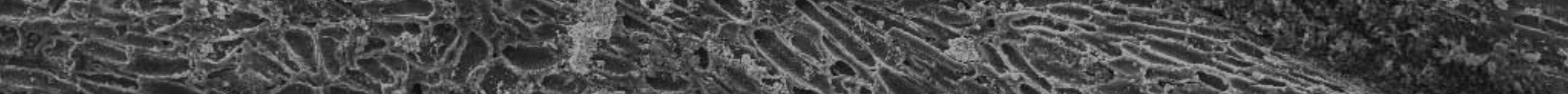

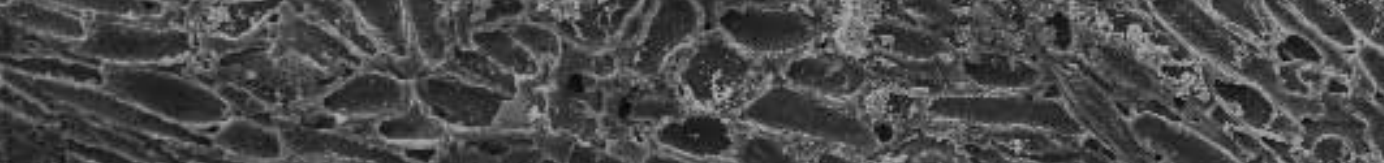

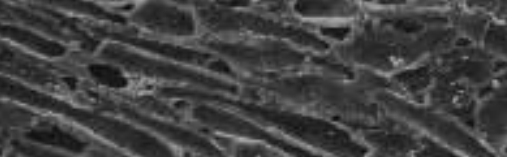




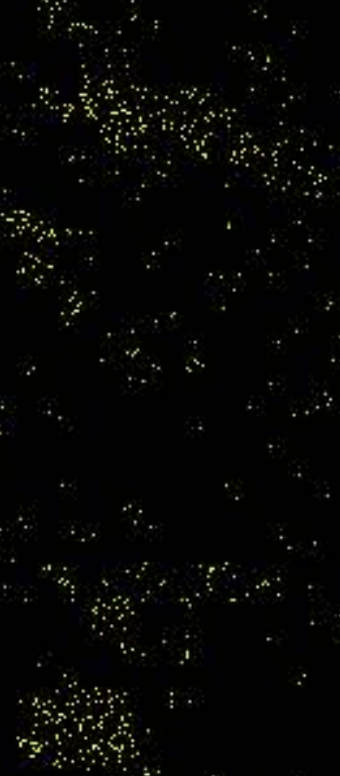

\section{$250 \mu \mathrm{m}$}




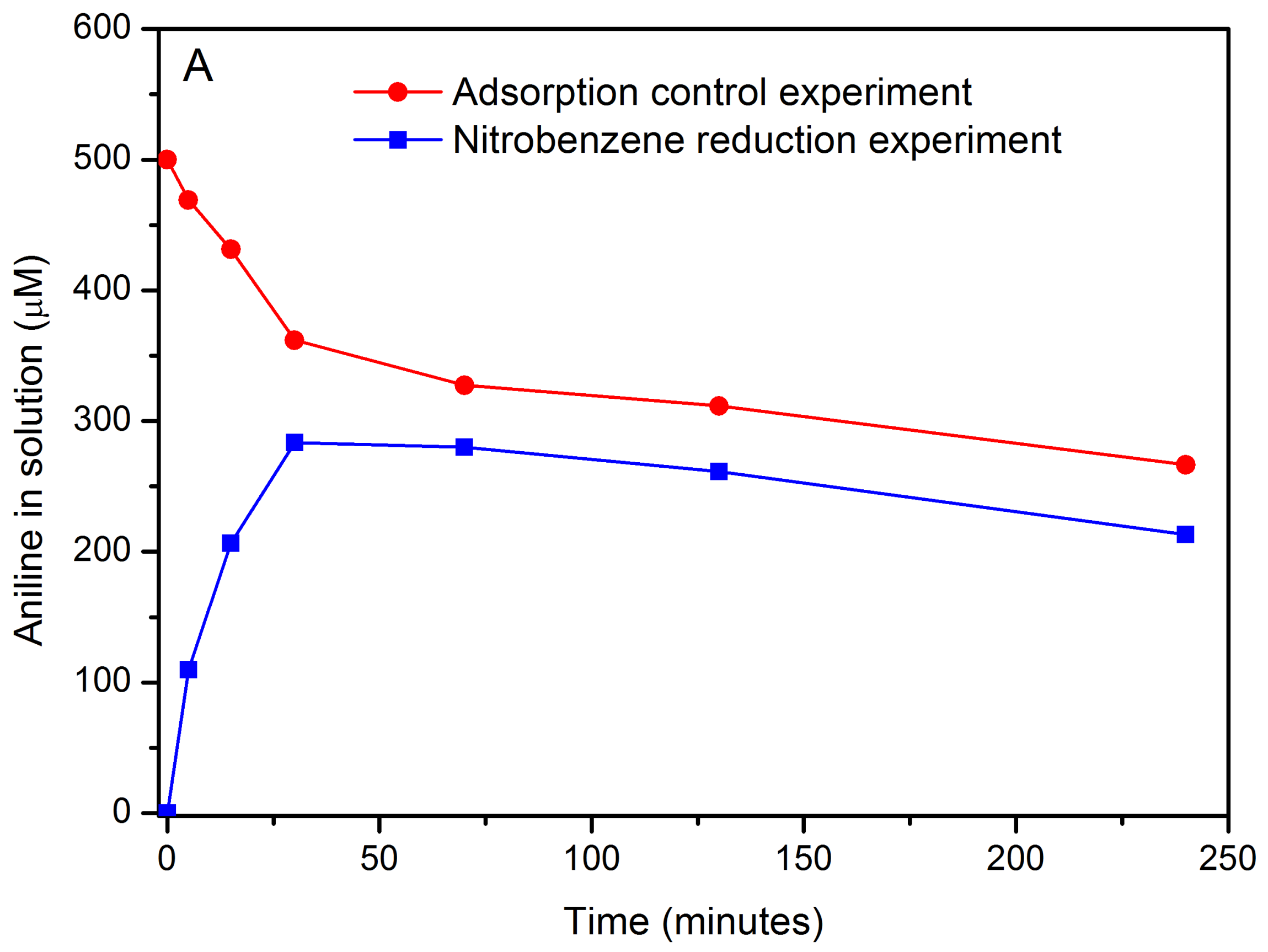




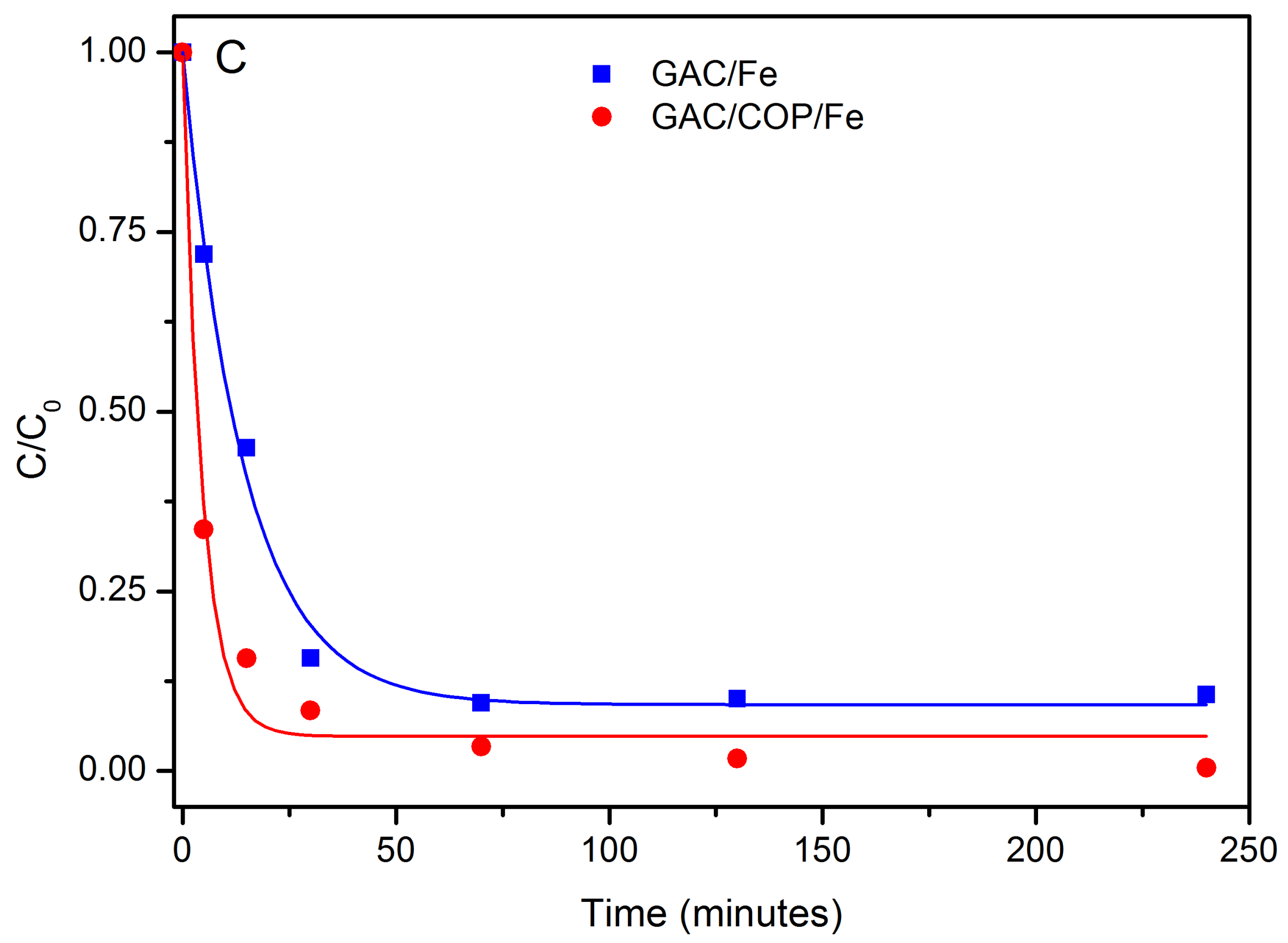




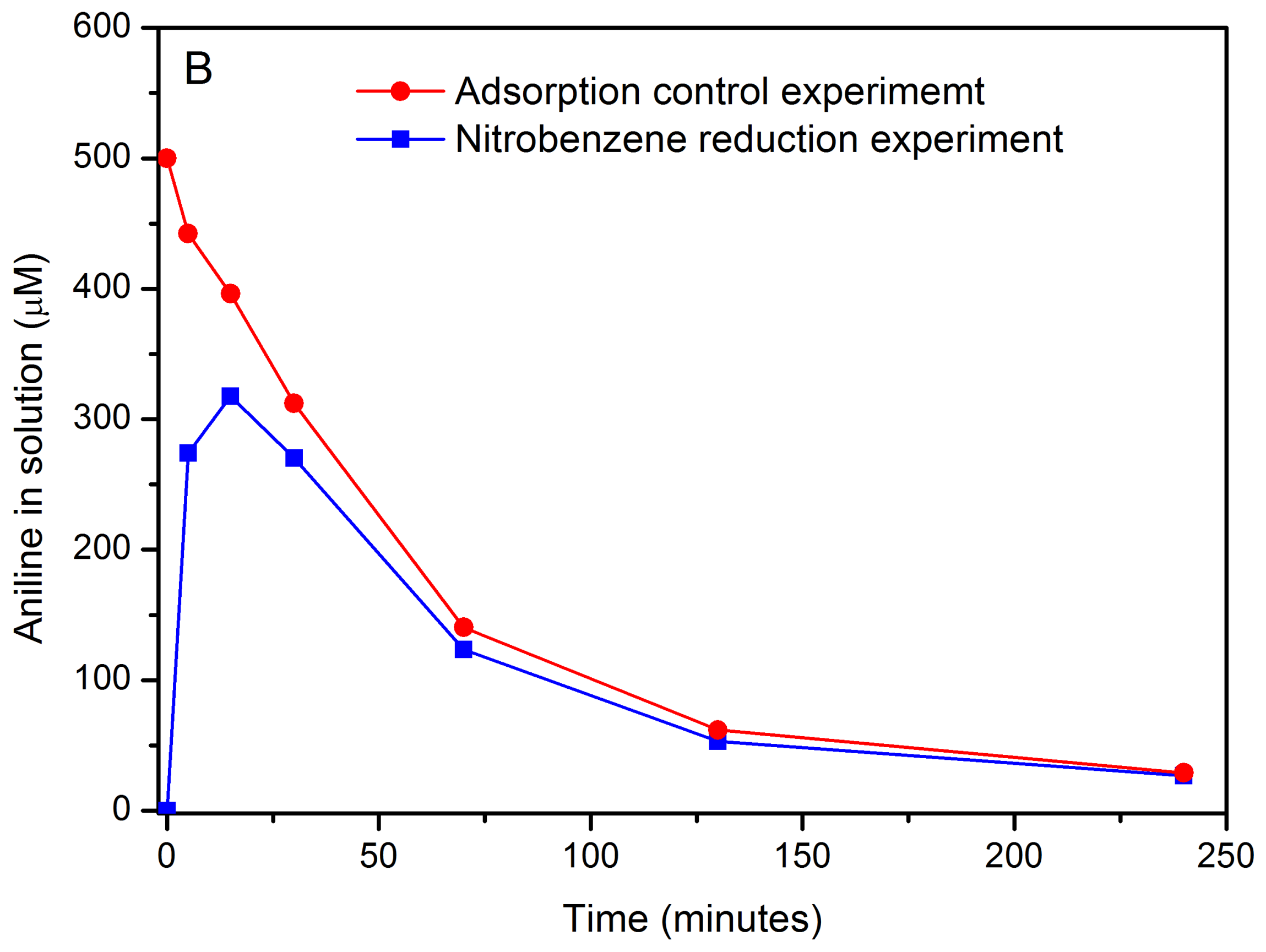




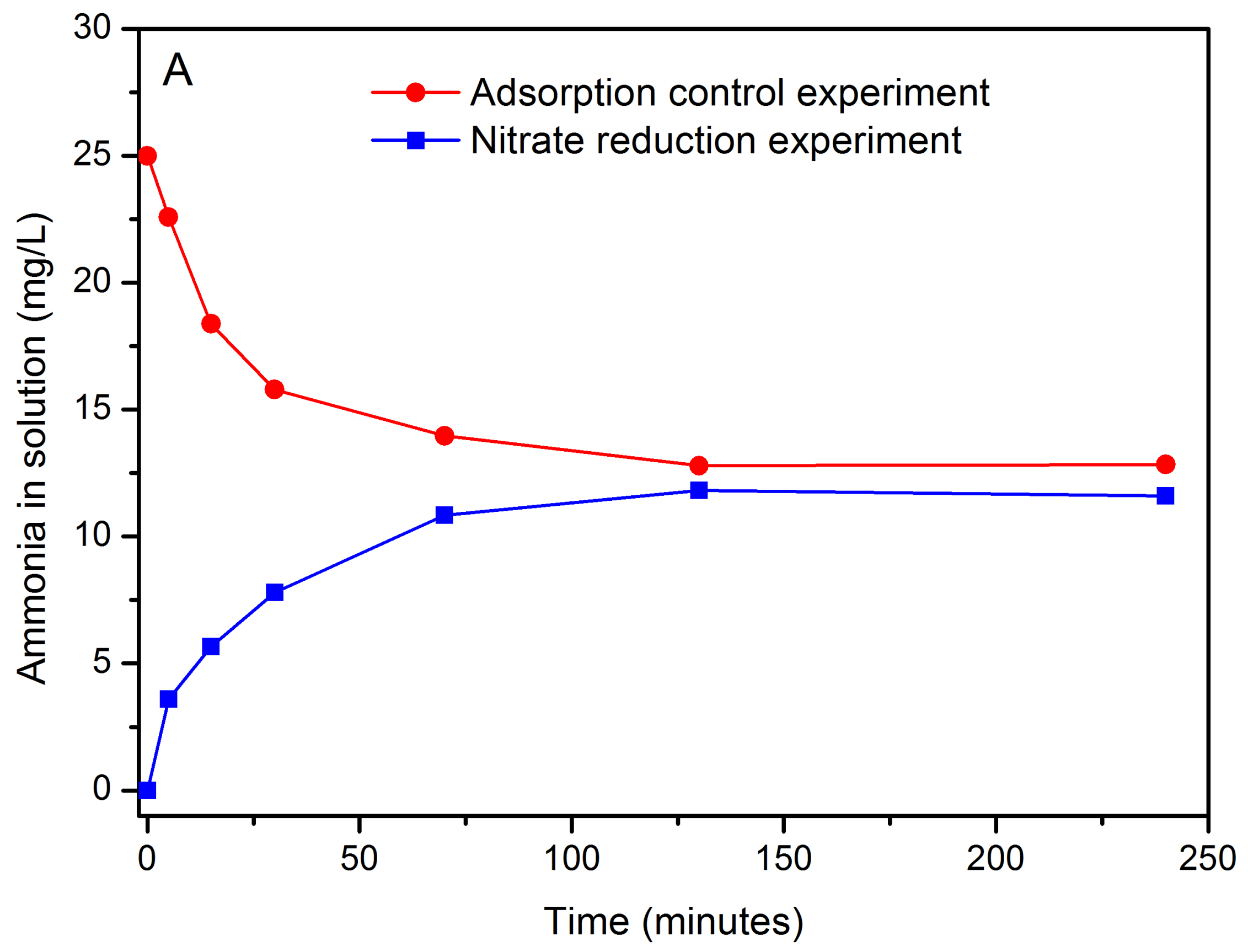




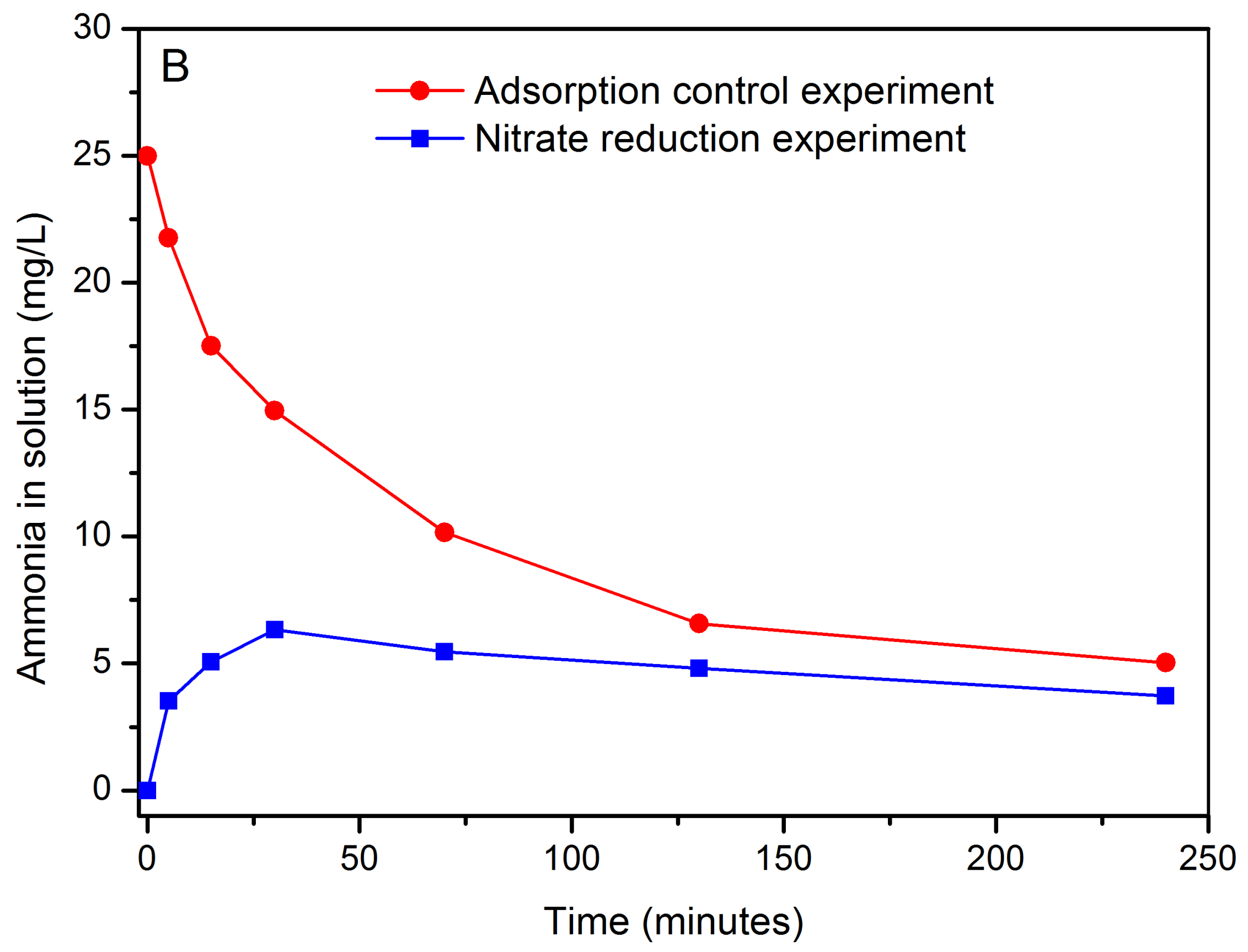




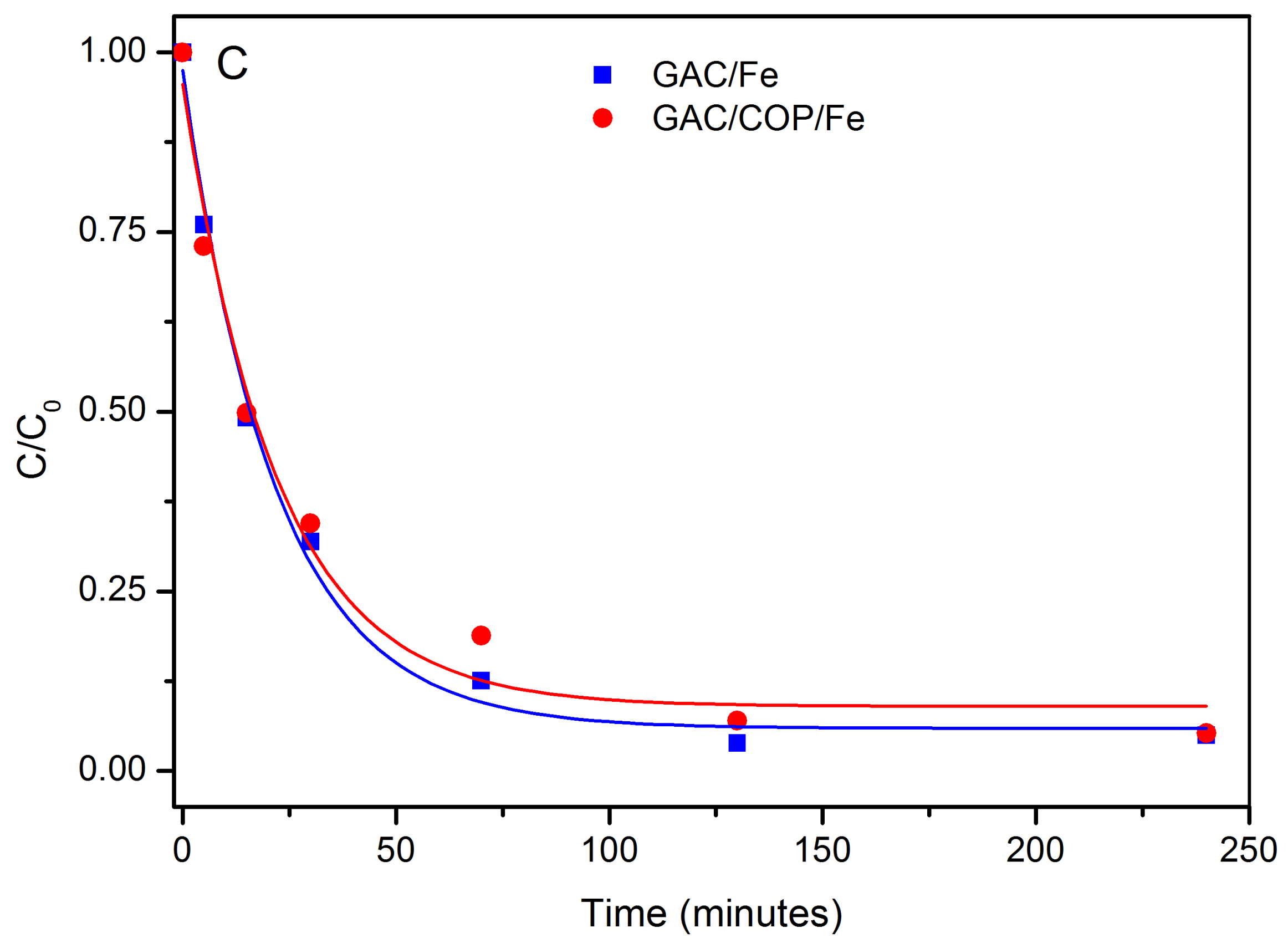


